\title{
Estrutura comunitária e amplitude ecológica do componente lenhoso de uma floresta de restinga mal drenada no sudeste do Brasil ${ }^{1}$
}

\author{
Luis Fernando Tavares de Menezes ${ }^{2,5}$, Dorothy Sue Dunn de Araujo ${ }^{3}$ e Felipe Cito Nettesheim ${ }^{4}$
}

Recebido em 2/02/2010. Aceito em 28/06/2010

RESUMO - (Estrutura comunitária e amplitude ecológica do componente lenhoso de uma floresta de restinga mal drenada no sudeste do Brasil). Analisamos a estrutura de uma floresta mal drenada na Restinga da Marambaia, RJ, e a amplitude ecológica das espécies quanto à tolerância à inundação do solo. Foram amostrados em 50 parcelas contíguas de $10 \mathrm{X} 10 \mathrm{~m}$ ( $0,5 \mathrm{ha}$ ), indivíduos com diâmetro do caule a altura do peito (DAP) $\geq 2,5 \mathrm{~cm}$. Registramos 1.223 indivíduos vivos (distribuídos em 24 famílias, 43 gêneros e 57 espécies). O índice de diversidade de Shannon (H’) foi de 2,87 e a equabilidade (J') foi de 0,68. A densidade total foi de 2.446 ind. ha ${ }^{-1}$ e a área basal de $25,14 \mathrm{~m}^{2}$. ha ${ }^{-1}$. As famílias mais ricas em espécies foram Myrtaceae (13), Leguminosae (5), Annonaceae, Euphorbiaceae, Myrsinaceae e Sapindaceae (4). Dez espécies apresentaram valor de importância (VI) acima de nove, correspondendo o somatório de seus valores a 75\% do VI total. As espécies com maiores valores de VI foram Tapirira guianensis Aubl. (42,42), Amaioua intermedia Mart. ex Roem. \& Schult. $(40,77)$ e Chaetocarpus myrsinites Baill. $(39,98)$, que juntas detiveram $41 \%$ do VI total. A comunidade arbórea analisada foi composta principalmente por espécies preferenciais de áreas secas, ou seja, espécies com preferência por alagamento periódico do solo ou solos mais secos, mas não com alagamento permanente ou quase permanente do solo. A maior similaridade da floresta mal drenada da Marambaia foi observada com as florestas inundáveis do Parque Nacional de Jurubatiba, RJ (21,4 e 23,8\%). Nossos resultados permitiram concluir que não existe uma flora particular para as formações inundáveis nas restingas do sul e sudeste brasileiro e que mudanças do padrão florístico da vegetação dessas áreas ocorrem em função da proximidade da fonte de propágulos de espécies com alta tolerância à inundação do solo e secundariamente relacionada a questões fitogeográficas, ligadas à limitação da distribuição de espécies pelas condições climáticas das regiões subtropicais.

Palavras-chave: diversidade, fitossociologia, floresta de restinga, formações vegetais, similaridade

ABSTRACT - (Woody-layer structure and ecological amplitude of a poorly drained beach-ridge forest in southeastern Brazil). We analyzed the structure of a seasonally flooded beach-ridge forest and species functional characteristics regarding soil flood tolerance at Restinga da Marambaia (Rio de Janeiro). We sampled 50 contiguous $10 \times 10 \mathrm{~m}$ plots $(0.5 \mathrm{ha})$ and recorded woody individuals with trunk breast height diameter $(\mathrm{dbh}) \geq 2.5 \mathrm{~cm}$. We found 1223 live trees, belonging to 24 families, 43 genera and 57 species. Shannon's index was 2.87 and equitability (J') 0.68 . Total estimated density and basal area were 2446 ind.ha ${ }^{-1}$ and $25.14 \mathrm{~m}^{2}$.ha ${ }^{-1}$. The most species-rich families were Myrtaceae (13), Leguminosae (5), Annonaceae, Euphorbiaceae, Myrsinaceae and Sapindaceae (4). Ten species had importance values (IV) over nine and included $75 \%$ of total IV. Species with high IV were Tapirira guianensis Aubl. (42.42), Amaioua intermedia Mart. ex Roem. \& Schult. (40.77) and Chaetocarpus myrsinites Baill. (39.98), which together hold 41\% of total IV. Results indicated that the tree community studied was mainly composed of species that prefer drier or periodically flooded soils, but not permanently flooded soils. The seasonally flooded forest in Restinga da Marambaia shows greatest similarity with seasonally flooded forests at Jurubatiba National Park - RJ (21.4\%; $23.8 \%$ ). Since the flora of seasonally flooded forests in southern and southeastern Brazilian restingas apparently is not restricted to these formations, it is reasonable to conclude that floristic pattern changes in the vegetation of these areas may be the result of the proximity of species' propagule sources (i.e., those with high soil flood tolerance), plus the phytogeography of the species linked to distribution limits caused by climatic conditions.

Key words: diversity, plant formations, phytosociology, similarity

\section{Introdução}

No Brasil, principalmente nas regiões sul e sudeste, as restingas têm sido alvo de estudos mais sistematizados, sobretudo levantamentos florísticos e estruturais, que evidenciam a importância desses ecossistemas para a biodiversidade. Tal importância reside no fato das espécies que ocorrem nas restingas serem, na sua maioria, formas adaptadas de espécies oriundas da mata tropical chuvosa e que se estruturam em comunidades através de processos de interação positiva entre poucas espécies (Scarano et al. 2001).

As restingas cobrem cerca de $79 \%$ do litoral brasileiro e compõem um mosaico de formações vegetais, florística e estruturalmente diferenciadas, variando desde aquelas com fisionomia herbácea, passando por formações arbustivas até florestais (Lacerda et al. 1993, Menezes \& Araujo 2005, Almeida Jr. et al. 2009). Frequentemente, essas formações encontram-se próximas umas das outras, não obstante as- sociadas a áreas topograficamente diferenciadas. O relevo varia desde depressões, que apresentam afloramento do lençol freático com períodos, intensidade e frequência de inundação variados, até ambientes não inundáveis devido à topografia mais elevada, como dunas e cristas de cordões arenosos (Pereira 1990, Waechter 1990, Araujo et al. 1998). Nesse sentido, uma das principais questões a ser investigada nas restingas é a determinação dos fatores responsáveis pela flora e estrutura das formações vegetais.

As formações florestais, em particular, apresentam fisionomias com altura do dossel a partir de $5 \mathrm{~m}$, em geral sobre solos bem drenados, até formações mais desenvolvidas, com alturas em torno de $20 \mathrm{~m}$, frequentemente associadas a solos ricos em matéria orgânica e com diferentes níveis de inundações (Araujo et al. 1998). Estudos recentes de caracterização de formações florestais ocorrentes nas restingas brasileiras têm considerado relevantes algumas características abióticas, tais como a geomorfologia, os tipos

\footnotetext{
1 Parte da tese de Doutorado do primeiro Autor

2 Centro Universitário Norte do Espírito Santo, Departamento de Ciências Agrárias e Biológicas, São Mateus, ES, Brasil

3 Instituto de Pesquisa Jardim Botânico do Rio de Janeiro, Rio de Janeiro, RJ, Brasil

4 Universidade Federal do Rio de Janeiro, Programa de Pós-Graduação em Ecologia, Rio de Janeiro, RJ, Brasil

5 Autor para correspondência: 1tmenezes@gmail.com
} 
de solos e a suscetibilidade à inundação, como critérios para a definição de fisionomias (Araujo et al. 1998, Assis et al. 2004, Menezes \& Araujo 2005, Silva \& Britez 2005).

As florestas que apresentam afloramento do lençol freático, descritas em estudos que propõem uma classificação de formações vegetais de restinga para diversos pontos do sul e sudeste brasileiro, têm sido designadas de acordo com o regime de inundação, como florestas periodicamente ou permanentemente inundadas (Araujo \& Henriques 1984, Pereira 1990, Pereira \& Gomes 1994, Araujo et al. 1998), matas turfosas e florestas paludosas (Waechter \& Jarenkow 1998). Uma tentativa de padronização do uso de terminologias para essas formações foi feita por Menezes \& Araujo (2005), seguindo, em parte, a classificação realizada para a Ilha do Mel, Paraná (Silva \& Britez 2005). Segundo estes autores, essas florestas foram designadas de inundadas (com afloramento do lençol freático constante, porém menos evidente no inverno e em períodos menos chuvosos) ou inundáveis (sujeitas a afloramentos temporários do lençol freático nos períodos mais chuvosos, podendo durar poucas horas, dias ou longos períodos). Esta classificação é usada no presente trabalho.

As diferenças na duração do período de alagamento em sistemas florestais geralmente implicam em diferenças na diversidade de espécies, e aquelas que são dominantes em florestas que sofrem inundação podem não ocorrer, ou serem raras, nas áreas mais secas (Ferreira \& Stohlgren 1999, Gomes et al. 2004). Desse modo, variações na frequência e intensidade da inundação do solo podem ser consideradas como fatores determinantes nas características estruturais e florísticas da vegetação, além de poderem resultar em alterações no comportamento de determinadas populações (Rodrigues \& Shepherd 2000, Silva et al. 2007). A inundação define características abióticas particulares, tanto em nível edáfico, quanto microclimático, que afetam significativamente os processos bióticos, como a taxa de decomposição (Pagano \& Durigan 2000), a germinação e o recrutamento de indivíduos (Lobo \& Joly 2000), de tal forma que acabam definindo a distribuição espacial das espécies na floresta.

Dentro da variabilidade fisionômica das formações vegetais ocorrentes na Restinga da Marambaia, RJ, destacam-se as florestas que ocupam trechos inundáveis pelo afloramento do lençol freático e outros onde o lençol freático aproxima-se da superfície do solo, atingindo a zona das raízes, mas sem afloramento (Menezes \& Araujo 2005). Esta condição parece ser semelhante à de outras florestas de restinga no sudeste brasileiro, descritas como não inundáveis, mas que nos períodos mais chuvosos apresentam inundações temporárias não prolongadas a poucos centímetros abaixo da superfície do solo (e.g. César \& Monteiro 1995, Guedes et al. 2006). A falta de detalhamentos sobre o regime de inundação nos trabalhos publicados tem dificultado a comparação dessa fisionomia com tipologias pré-estabelecidas (Menezes \& Araujo 2005), já que existem variações na periodicidade, duração e profundidade de alagamento (Silva et al. 2007).
Embora na última década tenha ocorrido um incremento no conhecimento sobre a florística e estrutura de florestas inundáveis em restingas no sul e sudeste brasileiro (Sztutman \& Rodrigues 2002, Dorneles \& Waechter 2004b, Guedes et al. 2006, Silva et al. 2007), esse tipo fisionômico no Rio de Janeiro tem recebido pouca atenção da comunidade científica. Assim, esse trabalho teve como objetivos: i) descrever a estrutura e composição florística de uma floresta mal drenada na Restinga da Marambaia, RJ, ii) avaliar a distribuição dos táxons em florestas de restinga com diferentes níveis de saturação hídrica no solo e iii) classificar ecologicamente as espécies, quanto à preferência de ocorrência em formações vegetais inundadas, inundáveis ou não inundáveis na costa sul e sudeste brasileira.

\section{Material e métodos}

Área de estudo - A Restinga da Marambaia, com aproximadamente 49,4 $\mathrm{km}^{2}$, localiza-se no sul do estado do Rio de Janeiro, compreendendo parte dos municípios do Rio de Janeiro, Itaguaí e Mangaratiba $\left(23^{\circ} 02^{\prime} \mathrm{S}\right.$ a $23^{\circ} 06^{\prime} \mathrm{S} ; 43^{\circ} 35^{\prime} \mathrm{W}$ a $43^{\circ} 54^{\prime} \mathrm{W}$. - Fig. 1). A floresta mal drenada estudada localiza-se na porção oeste da restinga e está associada aos feixes de cordões arenosos que deram origem às cúspides voltadas para dentro da Baía de Sepetiba. Estes feixes são topograficamente mais baixos do que o cordão arenoso interno, que é mais antigo e possui até $7 \mathrm{~m}$ de altura acima do nível do mar (Roncarati \& Menezes 2005). Segundo esses autores, as cúspides que se projetam para dentro da Baía de Sepetiba, partindo do cordão arenoso interno, formaram-se há pouco menos de 1.500 anos A.P. e constituem um conjunto de ondulações indicando a sucessão de deposição de cordões arenosos. A vegetação que recobre essa unidade geomorfológica é marcadamente influenciada pela topografia do terreno, ora associada a depressões entre os cordões, ora associada ao topo destes, constituindo um mosaico vegetacional formado por áreas inundáveis pelo afloramento do lençol freático e áreas onde o lençol não aflora, mas o solo apresenta-se com saturação hídrica nos períodos mais chuvosos.

A largura dos cordões arenosos varia de 30 a $100 \mathrm{~m}$ e as depressões entre estes variam de 6 a $15 \mathrm{~m}$. A fisionomia nas depressões é predominantemente marcada por Tabebuia cassinoides DC., ocorrendo também Annona glabra L., Miconia cinnamomifolia (DC.) Naudin, Calophyllum brasiliense Cambess., Tapirira guianensis Aubl.e Alchornea triplinervia (Spreng.) Müll.Arg..

Os dados climáticos foram obtidos pelo Instituto Nacional de Meteorologia (INMET), coletados entre os anos de 1986 a 1998, no posto meteorológico localizado na Restinga da Marambaia, a 9,7 m de altitude e a $50 \mathrm{~m}$ do mar, distando $35 \mathrm{~km}$ da área de estudo. Segundo a classificação de Köppen (1948), a região enquadra-se no macroclima Aw (clima tropical com chuvas sazonais de verão), com temperaturas do ar típicas das áreas litorâneas tropicais. A temperatura média anual é de $23,7^{\circ} \mathrm{C}$, sendo o mês de fevereiro o mais quente (média de $26,9^{\circ} \mathrm{C}$ ) e agosto, o mais frio (média de $20,9^{\circ} \mathrm{C}$ ). A precipitação média anual é de $1237,7 \mathrm{~mm}$, sendo que $37 \%$ deste valor ocorrem no verão, distribuídos em cerca de 40 dias chuvosos. Nos meses de inverno ocorrem $15 \%$ da precipitação média anual, distribuída em torno de 21 dias. Em julho e agosto a precipitação média mensal situa-se entre 40 e $55 \mathrm{~mm}$, já tendo, por diversos anos, ocorrido valores abaixo de $30 \mathrm{~mm}$, ocasionando acentuada seca na região (Mattos 2005).

Fertilidade do solo-A fertilidade do solo, nas profundidades 0-5, 5-10 e 10-20 $\mathrm{cm}$, foi avaliada por meio de 10 amostras, sendo cada uma coletada no centro de uma parcela sorteada entre as 50 utilizadas na amostragem fitossociológica. As amostras foram homogeneizadas por profundidade obtendo-se três amostras compostas. As amostras foram secadas ao ar, destorroadas e peneiradas. No material obtido, foram determinados o $\mathrm{pH}$ em água, os teores de carbono orgânico, Ca, Mg, K, Al, Na, P, H+Al, segundo EMBRAPA/CNPS (1997). As análises químicas foram feitas no laboratório de Fertilidade dos Solos do Departamento de Solos do Instituto de Agronomia da UFRRJ.

Avaliação do lençol freático - Próximo ao centro de cada parcela foi cavado um poço de $1,50 \mathrm{~m}$ de profundidade a fim de se avaliar a variação do nível 


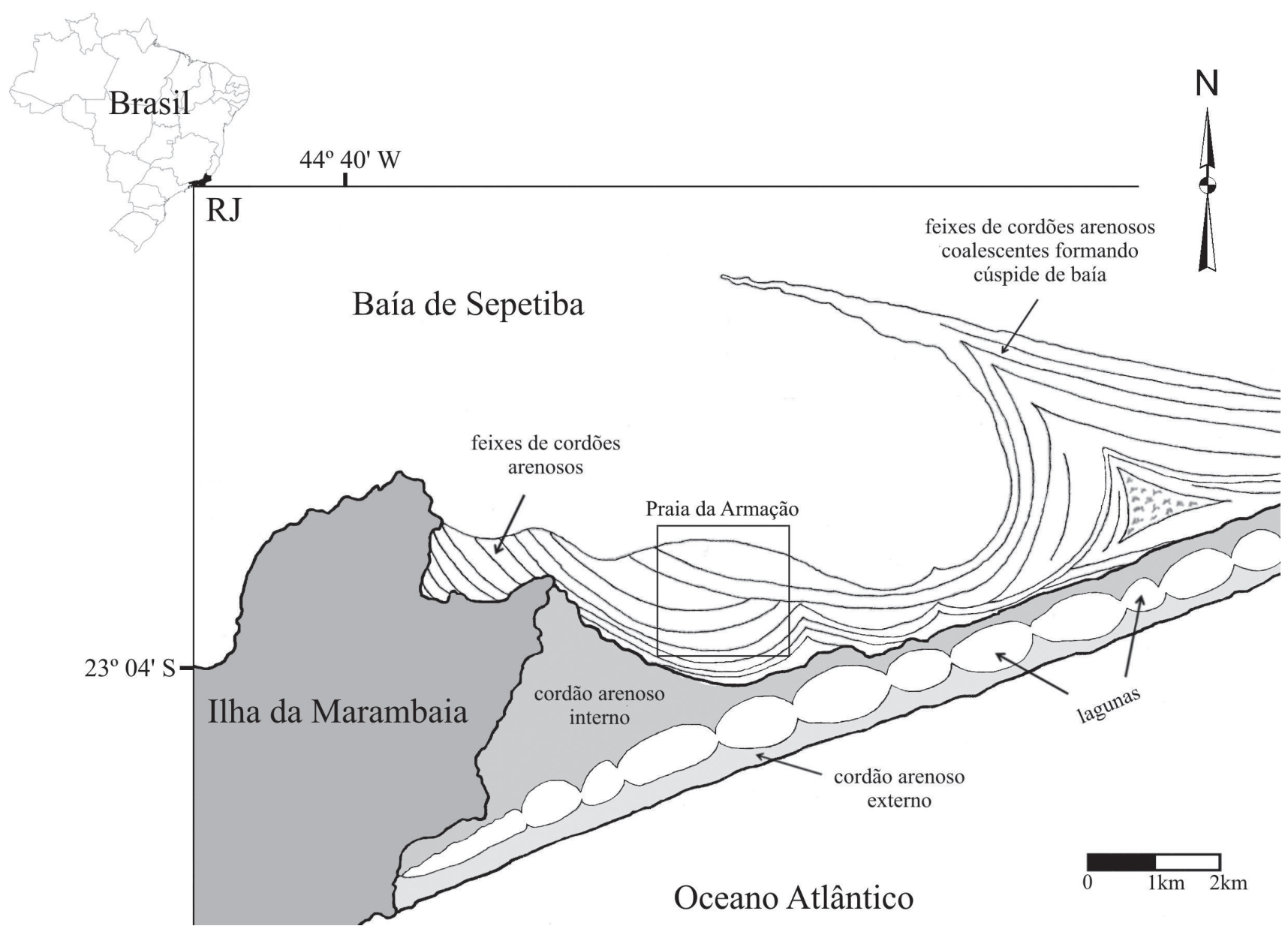

Figura 1. Localização da floresta mal drenada na Restinga da Marambaia, RJ, Brasil e delimitação da área de estudo, indicada pelo quadrado na Praia da Armação.

do lençol freático. A verificação da profundidade da água subterrânea foi feita diretamente através de uma régua graduada, medindo-se desde a superfície do solo até a lâmina d'água. Esse procedimento foi realizado no período de 11/2000 a 11/2007, em intervalos de aproximadamente 30 dias. Amostragem da vegetação - Foi realizado o levantamento em 0,5 ha da floresta mal drenada, situada sobre cordão arenoso, onde o afloramento do

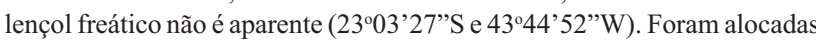
cinquenta parcelas contíguas de 10 x $10 \mathrm{~m}$ (Mueller-Dombois \& Ellenberg 1974), formando quatro faixas paralelas à linha da praia, sendo a primeira formada por 14 parcelas e as demais por 12 parcelas. A primeira faixa de parcelas distava $50 \mathrm{~m}$ da margem da Baía de Sepetiba. Foram incluídos no censo todos os indivíduos arbustivos ou arbóreos, inclusive os mortos ainda em pé, com $2,5 \mathrm{~cm}$ ou mais de diâmetro do tronco à altura do peito (DAP). Cada indivíduo amostrado recebeu uma plaqueta numerada e teve seu DAP medido. As alturas dos indivíduos foram estimadas visualmente, sempre pelo mesmo membro da equipe durante todo o levantamento. Em indivíduos perfilhados acima do solo e abaixo da altura do peito $(1,30 \mathrm{~m})$, só foram marcados e medidos quando um dos ramos obedecia ao critério de inclusão, sendo então anotado o DAP de todas as ramificações para o cálculo da área basal

Simultaneamente ao levantamento estrutural, foram coletadas amostras para herborização, de acordo com técnicas usuais (Fidalgo \& Bononi 1984) e incorporadas ao acervo do Herbário da Universidade Federal Rural do Rio de Janeiro (RBR). As identificações botânicas foram feitas por meio de obras clássicas e revisões, comparações com exsicatas já identificadas existentes nos herbários RBR, RB (Instituto de Pesquisa Jardim Botânico do Rio de Janeiro) e GUA (Fundação Estadual de Engenharia do Meio Ambiente) ou consultas a especialistas.
Análise de dados - A formação foi caracterizada utilizando descritores fitossociológicos absolutos e relativos de densidade, dominância, frequência e valor de importância (Brower \& Zar 1984). A diversidade específica foi calculada utilizando-se o Índice de Shannon (H') e a equabilidade de Pielou (Magurran 1988). Todos os cálculos foram realizados com o auxílio do programa FITOPAC (Shepherd 1996). Para a área de estudo, foi avaliada a distribuição de densidade de árvores por classes de diâmetro e de altura. Para a determinação da amplitude das classes, utilizou-se a fórmula proposta por Spiegel (1977). Conforme recomendações de Oliveira Filho et al. (2001), no caso dos diâmetros, foram empregados intervalos de classe com amplitudes crescentes para compensar o forte decréscimo da densidade nas maiores classes de tamanho, típico da distribuição em J-invertido.

Para a comparação florística entre a área estudada e outras florestas de restinga do sul e sudeste do Brasil, com diferentes níveis de saturação hídrica do solo, foram reunidos 20 levantamentos fitossociológicos, incluindo o presente estudo. As áreas analisadas foram designadas nas tabelas de forma numérica, onde o Estado, a condição de inundação do solo e a referência bibliográfica: 1 - Dillenburg et al. (1992) (RS); 2 -Assumpção \& Nascimento (2000) (RJ); 3 - Waechter et al. (2000) (RS); 4 - Dorneles \& Waechter (2004b) (RS); 5 Assis et al. (2004) (ES); 6 - Guedes et al. (2006) Área II (SP); 7 - Scherer et al. (2005); 8 - Sá \& Araujo (2009) (RJ); 9 - César \& Monteiro (1995) (SP); 10 - Silva et al. (1994) (PR); 11 - Sugiyama (1998) (SP - Área I); 12 - Sugiyama (1998) (SP - Área II); 13 - R.C. Oliveira, dados não publicados (RJ); 14 - M.J. Barros (dados não publicados) (RJ); 15 - Guedes et al. (2006) Área I (SP); 16 - Waechter \& Jarenkow (1998) (RS); 17 - Sztutman \& Rodrigues (2002 - turfeira rasa) (SP); 18 - Sztutman \& Rodrigues (2002 - turfeira profunda) (SP); 19 - Dorneles \& Waechter (2004a) (RS); 20 - o presente estudo. De um a oito incluem-se as florestas não inundáveis de restinga e de 9 a 20, 
incluem-se as florestas inundáveis e inundadas de restinga. Estas 20 áreas foram usadas para compilar uma matriz com os dados de presença/ausência das espécies nelas ocorrentes. Foram eliminados os táxons com identificação apenas nos níveis de gênero e família e verificadas as sinonímias. Para esta análise foram incluídas espécies de baixa densidade (inclusive aquelas que ocorreram apenas em uma localidade) como parte dos processos estocásticos determinantes das comunidades (Hubbell 2001, Magurran 2004). As áreas foram então comparadas por uma análise de agrupamento utilizando o coeficiente de Jaccard (Valentin 2000). O agrupamento das áreas foi feito segundo o método de ligação UPGMA (Unweighted Pair Group Method using Arithmetic Averages).

As espécies do levantamento estrutural foram classificadas segundo sua preferência por áreas alagadas, como proposto por Ivanauskas et al. (1997) e Carvalho et al. (2006), com modificações: (1) espécies exclusivas - de ocorrência exclusiva em florestas inundadas (permanentemente ou quase), ocorrendo, pelo menos em três áreas analisadas e seu destaque na estrutura da comunidade está diretamente ligado a um maior período de saturação hídrica do solo; (2) espécies seletivas - destacam-se em florestas sujeitas à inundação periódica do solo, mas nunca em áreas com inundação permanente ou quase permanente do solo ou em outras florestas com solos melhor drenados; (3) espécies preferenciais de áreas bem drenadas - destacam-se em florestas com inundação periódica do solo ou em florestas bem drenadas, mas nunca em florestas com inundação permanente ou quase permanente do solo e (4) espécies indiferentes - ocorrem em áreas inundadas, contudo sua abundância e densidade não têm relação direta com a inundação e podem se destacar em qualquer ambiente. Para subsidiar tal classificação, tomou-se como base o estudo de Menezes \& Araujo (2005) que fornece a distribuição de espécies da Restinga da Marambaia por formação vegetal. Considerou-se ainda a presença ou ausência das espécies aqui listadas nas formações vegetais dos 19 estudos de restingas do sul e sudeste brasileiro, utilizados na análise da similaridade florística (Tab. 2).

O sistema de classificação taxonômica adotado foi o proposto por APG II (2003). As abreviações dos autores dos binômios específicos foram verificadas em Brummitt \& Powell (1992).

\section{Resultados e discussão}

Fertilidade do solo - O solo da área de estudo foi identificado como Neossolo Quartzarênico e apresentou baixo teor de matéria orgânica (Tab. 1), sendo este valor inferior a de outras florestas de restinga mal drenadas (Guedes et al. 2006). Solos de florestas de restinga inundáveis, de maneira geral, apresentam maior teor de matéria orgânica em relação a solos de florestas de restinga bem drenados. Esta condição é decorrente da presença do lençol freático próximo à superfície, que retarda a decomposição da matéria orgânica pela via aeróbica e modifica as características físicas e químicas do solo (Lobo \& Joly 2000). De fato, a inundação afeta a quantidade de oxigênio disponível no solo, altera a presença de microorganismos decompositores e o processo respiratório das raízes (Toniato et al. 1998). Como os solos de restinga apresentam textura arenosa, a matéria orgânica passa a desempenhar um papel de fundamental importância, influenciando diretamente, tanto o estoque de nutrientes, quanto na CTC (capacidade de troca catiônica) (Hay \& Lacerda 1984). Os teores de matéria orgânica regulam a CTC, principalmente em solos tropicais, cuja fase mineral é dominada por minerais de baixa atividade química, quando comparada à fase mineral dos solos encontrados em regiões de clima temperado. Em solos brasileiros, a matéria orgânica pode contribuir para até $80 \%$ das cargas negativas do solo, e isso explica o fato da CTC desses solos estarem, em grande parte, associada à matéria orgânica (van Raij 1969).
De maneira geral, a fertilidade do solo foi considerada baixa, quando comparada com a de outros sistemas florestais tropicais não inundáveis (Moraes et al. 1999). Os teores de carbono orgânico, $\mathrm{K}, \mathrm{Na}, \mathrm{P}, \mathrm{Ca}+\mathrm{Mg}, \mathrm{Al}$ e H+Al diminuíram de acordo com a profundidade do solo, indicando que os primeiros cinco centímetros da camada de solo constituem a maior fonte de nutrientes para as plantas. Com exceção desses macronutrientes, todos os outros analisados apresentaram concentrações baixas nas profundidades estudadas.

Os valores de $\mathrm{pH}$ encontrados foram considerados baixos e caracterizam o solo como fortemente ácido. A condição de pH baixo limita a presença de organismos decompositores, consequentemente aumenta o tempo para a degradação do material vegetal, o que permite a formação de uma espessa camada de serrapilheira. A degradação lenta da serrapilheira promove um retorno gradual de nutrientes para o solo e minimiza as perdas por lixiviação (Moraes et al. 1999).

Os teores de alumínio foram considerados altos, como o observado em outras áreas de florestas que apresentam solos inundáveis (Toniato et al. 1998, Guedes et al. 2006). Esta condição é decorrente da acidez do solo que promove o aparecimento do $\mathrm{Al}$ em solução, tornando-se um cátion trocável $\left(\mathrm{Al}^{+++}\right)$que, em determinadas concentrações, tornase tóxico para a vegetação (Ponnamperuma 1984). Como a diversidade e o desenvolvimento estrutural da vegetação na área de estudo foram considerados altos, quando comparados com outras áreas de restinga inundáveis, a presença de $\mathrm{Al}^{+++}$ parece não causar níveis de toxidade para a vegetação.

Variação do lençol freático - Nas depressões entre cordões arenosos verificou-se a formação de vales que inundam na época das chuvas, o que durante o período de estudo ocorreu entre os meses de abril a junho e formou alagadiços com até $70 \mathrm{~cm}$ de profundidade que permaneceram inundados por até quatro meses. Sobre os cordões arenosos, onde foram dispostas as parcelas para o levantamento estrutural, o lençol freático não aflorou, mas aproximou-se da superfície do solo (ca. 15-25 cm de profundidade), deixando a zona de raízes das plantas com saturação hídrica. Esta parece ser uma situação recorrente nas formações florestais em restingas onde a topografia do terreno eleva-se poucos metros acima no nível do mar, que por vezes contribui para o maior desenvolvimento estrutural da floresta (Araujo et al. 1998).

Diversidade e estrutura da formação - Nas parcelas foram registradas 57 espécies, distribuídas em 43 gêneros e 24 famílias (Tab. 2). Próximo à área de amostragem ainda foram constatadas Psidium cattleyanum Sabine, Blepharocalyx salicifolius (Humboldt, Bonpland \& Kunth) Berg e Hedyosmum brasiliense Mart.

As famílias com maior riqueza específica foram Myrtaceae, com 13 espécies (22,8\%); Leguminosae, com cinco espécies (8,8\%) e Annonaceae, Euphorbiaceae, Myrsinaceae e Sapindaceae, cada uma com quatro espécies $(7,0 \%)$. As 18 famílias restantes apresentaram uma ou duas espécies. 
Tabela 1. Teores de macronutrientes, acidez, alumínio e capacidade de troca catiônica (CTC) no solo de um trecho da floresta mal drenada na Restinga da Marambaia, RJ, Brasil.

\begin{tabular}{|c|c|c|c|c|c|c|c|c|c|c|c|}
\hline Profundidade $(\mathrm{cm})$ & $\mathrm{C}$ orgânico $\left(\mathrm{g} \mathrm{kg}^{-1}\right)$ & $\begin{array}{c}\mathrm{K} \\
\left(\mathrm{mg} \mathrm{kg}^{-1}\right)\end{array}$ & $\mathrm{Na}^{*}$ & $\mathrm{P}^{*}$ & $\mathrm{Ca}+\mathrm{Mg}^{*}$ & $\mathrm{Ca}^{*}$ & $\mathrm{Mg}^{*}$ & $\mathrm{Al}^{*}$ & $\mathrm{H}+\mathrm{Al}^{*}$ & $\mathrm{pH}^{*}$ & CTC* $^{*}$ \\
\hline $0-5$ & 8,10 & 21,84 & 0,06 & 0,91 & 1,30 & 0,30 & 1,00 & 1,50 & 14,02 & 3,2 & 2,91 \\
\hline $5-10$ & 8,07 & 20,28 & 0,04 & 0,50 & 0,50 & 0,40 & 0,10 & 1,40 & 8,25 & 3,5 & 1,99 \\
\hline $10-20$ & 7,46 & 17,16 & 0,03 & 0,34 & 0,30 & 0,20 & 0,10 & 1,00 & 7,92 & 3,4 & 1,37 \\
\hline
\end{tabular}

* $\mathrm{cmol}_{\mathrm{c}} / \mathrm{kg}$ de solo

Tabela 2. Espécies ocorrentes na floresta mal drenada na Restinga da Marambaia, RJ, Brasil. A numeração corresponde a outras florestas de restinga onde estas espécies se fazem presente (indicadas na metodologia). $\mathrm{PA}=$ preferência por área inundada $(\mathrm{Se}=$ espécie seletiva; Ps = espécie preferencial de área bem drenada; In = espécie indiferente).

\begin{tabular}{|c|c|c|c|c|c|c|c|c|c|c|c|c|c|c|c|c|c|c|c|c|c|}
\hline \multirow{2}{*}{ Família /Espécie } & \multirow{2}{*}{ Referência } & \multirow{2}{*}{$\mathrm{PA}$} & \multicolumn{8}{|c|}{ Florestas não inundáveis } & \multicolumn{11}{|c|}{ Florestas inundáveis ou inundadas } \\
\hline & & & 1 & 2 & 3 & 4 & 5 & 6 & 7 & 8 & 9 & 10 & 11 & 12 & 13 & 14 & 15 & 16 & 17 & 18 & 19 \\
\hline \multicolumn{22}{|l|}{ ANACARDIACEAE } \\
\hline Tapirira guianensis Aubl. & D.Araujo 10542 & In & & & & & & - & & & $\bullet$ & & & & $\bullet$ & $\bullet$ & $\bullet$ & & $\bullet$ & & \\
\hline \multicolumn{22}{|l|}{ ANNONACEAE } \\
\hline Annona glabra $\mathrm{L}$. & L.F.Menezes 595 & $\mathrm{Se}$ & & & & & & & & & & & & & & & & & & & \\
\hline Anaxagorea dolichocarpa Sprague \& Sandwith & L.F.Menezes 660 & Ps & & & & & & & & & & & & & & & & & & & \\
\hline Xylopia ochrantha Mart. & L.F.Menezes 638 & Ps & & & & & & & & & & & & & & & & & & & \\
\hline Xylopia sericea A.St.-Hil. & L.F.Menezes 217 & Ps & & & & & & & & & & & & & & & & & & & \\
\hline \multicolumn{22}{|l|}{ APOCYNACEAE } \\
\hline Aspidosperma parvifolium A.DC. & L.F.Menezes 715 & In & & & & & - & & & $\bullet$ & & & & & - & & & & & & \\
\hline \multicolumn{22}{|l|}{ AQUIFOLIACEAE } \\
\hline Ilex integerrima (Vell.) Reissek & L.F.Menezes 757 & $\mathrm{Se}$ & & & & & & & & & $\bullet$ & & $\bullet$ & $\bullet$ & $\bullet$ & & & & & & \\
\hline \multicolumn{22}{|l|}{ ARECACEAE } \\
\hline Syagrus romanzoffiana (Cham.) Glassman & L.F.Menezes $\mathrm{s} / \mathrm{n}^{\circ}$ & Ps & & & $\bullet$ & & & & $\bullet$ & & & & & & & $\bullet$ & & $\bullet$ & & & $\bullet$ \\
\hline \multicolumn{22}{|l|}{ BURSERACEAE } \\
\hline \multicolumn{22}{|l|}{ CELASTRACEAE } \\
\hline Maytenus robusta Reissek & L.F.Menezes 670 & Ps & & - & & & & - & & & & & & $\bullet$ & & & & & $\bullet$ & & \\
\hline \multicolumn{22}{|l|}{ CHLORANTHACEAE } \\
\hline Hedyosmum brasiliense Mart. * & L.F.Menezes 381 & $\mathrm{Se}$ & & & & & & $\bullet$ & & & & $\bullet$ & & & & & & & & & \\
\hline \multicolumn{22}{|l|}{ CLUSIACEAE } \\
\hline Garcinia brasiliensis Mart. & D.Araujo 9777 & In & & $\bullet$ & & & $\bullet$ & & & & $\bullet$ & & & & $\bullet$ & $\bullet$ & & & & & \\
\hline Calophyllum brasiliense Cambess. & L.F.Menezes 207 & $\mathrm{Se}$ & & & & & & - & & & - & $\bullet$ & $\bullet$ & $\bullet$ & $\bullet$ & $\bullet$ & $\bullet$ & & $\bullet$ & & \\
\hline \multicolumn{22}{|l|}{ CHRYSOBALANACEAE } \\
\hline Couepia schottii Fritsch & D.Araujo 10612 & In & & & & & & & & $\bullet$ & & & & & & & & & & & \\
\hline \multicolumn{22}{|l|}{ ELAEOCARPACEAE } \\
\hline Sloanea guianensis (Aubl.) Benth. & L.F.Menezes 1105 & $\mathrm{Se}$ & & & & & & - & & & & & & & $\bullet$ & & $\bullet$ & & & & \\
\hline \multicolumn{22}{|l|}{ EUPHORBIACEAE } \\
\hline Actinostemon communis (Müll.Arg.) Pax. & L.F.Menezes 718 & Ps & & & & & & & & & & & & & & & & & & & \\
\hline Alchornea triplinervia (Spreng.) Müll.Arg. & L.F.Menezes 557 & $\mathrm{Se}$ & & & & & & - & & & • & $\bullet$ & $\bullet$ & & $\bullet$ & • & $\bullet$ & & $\bullet$ & & \\
\hline Chaetocarpus myrsinites Baill. & D.Araujo 10553 & Ps & & & & & & & & & & & & & & & & & & & \\
\hline Pera glabrata (Schott) Baill. & D.Araujo 9886 & In & & $\bullet$ & & & $\bullet$ & $\bullet$ & & & $\bullet$ & $\bullet$ & $\bullet$ & $\bullet$ & $\bullet$ & $\bullet$ & $\bullet$ & & $\bullet$ & & \\
\hline \multicolumn{22}{|l|}{ LAURACEAE } \\
\hline Ocotea notata $(\mathrm{Nees}) \mathrm{Mez}$ & D.Araujo 9762 & In & & & & & & & & & & & & & - & $\bullet$ & & & & & \\
\hline Ocotea pulchella (Nees) Mez & D.Araujo 9774 & Ps & $\bullet$ & & & & & - & $\bullet$ & & & $\bullet$ & $\bullet$ & $\bullet$ & & & & $\bullet$ & $\bullet$ & $\bullet$ & $\bullet$ \\
\hline \multicolumn{22}{|l|}{ LEGUMINOSAE FAB } \\
\hline Andira fraxinifolia Benth. & D.Araujo 9763 & $\mathrm{Se}$ & & & & & $\bullet$ & - & & & $\bullet$ & $\bullet$ & $\bullet$ & $\bullet$ & • & - & - & & $\bullet$ & & \\
\hline Andira legalis (Vell.) Toledo & D.Araujo 9979 & Ps & & & & & & & & $\bullet$ & & & & & & & & & & & \\
\hline Ormosia arboea (Vell.) Harms & D.Araujo 10549 & $\mathrm{Se}$ & & & & & - & & & & & & $\bullet$ & & - & $\bullet$ & & & & & \\
\hline
\end{tabular}


Tabela 2. Continuação.

\begin{tabular}{|c|c|c|c|c|c|c|c|c|c|c|c|c|c|c|c|c|c|c|c|c|c|}
\hline \multirow{2}{*}{ Família /Espécie } & \multirow{2}{*}{ Referência } & \multirow{2}{*}{ PA } & \multicolumn{8}{|c|}{ Florestas não inundáveis } & \multicolumn{11}{|c|}{ Florestas inundáveis ou inundadas } \\
\hline & & & 1 & 2 & 3 & 4 & 5 & 6 & 7 & 8 & 9 & 10 & 11 & 12 & 13 & 14 & 15 & 16 & 17 & 18 & 19 \\
\hline \multicolumn{22}{|l|}{ LEGUMINOSAE MIM. } \\
\hline Inga laurina (Sw.) Willd. & L.F.Menezes 264 & $\mathrm{Se}$ & & $\bullet$ & & & & & & & & & & & $\bullet$ & $\bullet$ & & & & & \\
\hline $\begin{array}{l}\text { Pseudopiptadenia contorta (DC.) G.P.Lewis \& } \\
\text { M.P.Lima }\end{array}$ & L.F.Menezes 213 & Ps & & & & & & & & $\bullet$ & & & & & & & & & & & \\
\hline \multicolumn{22}{|l|}{ MELASTOMATACEAE } \\
\hline Miconia cinnamomifolia (DC.) Naudin & M.S.Conde 478 & $\mathrm{Se}$ & & & & & & & & & & & & & $\bullet$ & & & & & & \\
\hline \multicolumn{22}{|l|}{ MYRSINACEAE } \\
\hline Cybianthus sp. nova & L.F.Menezes 793 & $\mathrm{Se}$ & & & & & & & & & & & & & & & & & & & \\
\hline Myrsine guianensis (Aubl.) O.Kuntze & L.F.Menezes 717 & Ps & & & & & $\bullet$ & & $\bullet$ & & & & & & & & & & & & \\
\hline Myrsine parvifolia (A.DC) Mez & D.Araujo 9546 & Ps & & $\bullet$ & & & & & & & & & & & & & & & & & \\
\hline Myrsine venosa A. DC. & L.F.Menezes 583 & $\mathrm{Se}$ & & & & & & $\bullet$ & & & & $\bullet$ & & & & & $\bullet$ & & $\bullet$ & & \\
\hline \multicolumn{22}{|l|}{ MYRTACEAE } \\
\hline $\begin{array}{l}\text { Blepharocalyx salicifolius (Humboldt, } \\
\text { Bonpland } \\
\text { \& Kunth) Berg * }\end{array}$ & M.C.Souza 165 & Ps & & & $\bullet$ & $\bullet$ & $\bullet$ & & & & & $\bullet$ & $\bullet$ & $\bullet$ & & & & $\bullet$ & $\bullet$ & & \\
\hline Calyptranthes brasiliensis DC. & L.F.Menezes 698 & Ps & & & & & & & & & & & & & $\bullet$ & $\bullet$ & & & & & \\
\hline Eugenia brasiliensis Lam. & L.F.Menezes 632 & Ps & & & & & & & & $\bullet$ & & & & & & & & & & & \\
\hline Eugenia punicifolia (Kunth) DC. & L.F.Menezes 327 & Ps & & & & & $\bullet$ & & & $\bullet$ & & & & & & & & & & & \\
\hline Eugenia rostrata $\mathrm{O}$. Berg & L.F.Menezes 649 & Ps & & & & & $\bullet$ & & & & & & & & & & & & & & \\
\hline Eugenia sulcata Spreng. ex Mart. & L.F.Menezes 627 & Ps & & $\bullet$ & & & & $\bullet$ & & & & $\bullet$ & & & & & $\bullet$ & & & & \\
\hline Eugenia bahiensis DC. & L.F.Menezes 643 & Ps & & & & & & & & $\bullet$ & & & & & & & & & & & \\
\hline Gomidesia fenzliana Berg & M.C.Souza 218 & In & & & & & $\bullet$ & & & & & $\bullet$ & $\bullet$ & $\bullet$ & $\bullet$ & $\bullet$ & & & $\bullet$ & & \\
\hline Gomidesia martiana Berg & L.F.Menezes 889 & Ps & & & & & $\bullet$ & & & $\bullet$ & & & & & & & & & & & \\
\hline Myrcia acuminatissima O. Berg. & L.F.Menezes 267 & Ps & & & & & $\bullet$ & $\bullet$ & & & & $\bullet$ & $\bullet$ & & & $\bullet$ & $\bullet$ & & $\bullet$ & & \\
\hline Myrcia lundiana Kiaersk. & M.C.Souza 207 & Ps & & & & & & & & & & & & & & & & & & & \\
\hline Myrcia multiflora (Lam.) DC. & L.F.Menezes 672 & Ps & & & & & & $\bullet$ & & $\bullet$ & $\bullet$ & $\bullet$ & $\bullet$ & $\bullet$ & $\bullet$ & & $\bullet$ & & $\bullet$ & & $\bullet$ \\
\hline Myrcia recurvata O. Berg. & L.F.Menezes 640 & Ps & & & & & & & & & & & & & & & & & & & \\
\hline Psidium cattleyanum Sabine $*$ & L.F.Menezes 669 & In & & $\bullet$ & $\bullet$ & & & & $\bullet$ & & $\bullet$ & $\bullet$ & $\bullet$ & $\bullet$ & $\bullet$ & $\bullet$ & & $\bullet$ & $\bullet$ & & $\bullet$ \\
\hline $\begin{array}{l}\text { Myrciaria floribunda (H. West ex Willd.) } \\
\text { Legrand }\end{array}$ & M.C.Souza 158 & Ps & & & & & & & & & & & & & & & & & & & \\
\hline \multicolumn{22}{|l|}{ NYCTAGINACEAE } \\
\hline Guapira opposita (Vell.) Reitz & D.Araujo 9549 & In & $\bullet$ & & $\bullet$ & $\bullet$ & $\bullet$ & $\bullet$ & $\bullet$ & $\bullet$ & & $\bullet$ & & & $\bullet$ & $\bullet$ & $\bullet$ & & $\bullet$ & & $\bullet$ \\
\hline \multicolumn{22}{|l|}{ OCHNACEAE } \\
\hline Ouratea cuspidata (A.St.-Hil.) Engl. & D.Araujo 1656 & Ps & & & & & & & & & & & & & & & & & & & \\
\hline Ouratea miersii (Planch.) Engl. & L.F.Menezes 671 & Ps & & & & & & & & & & & & & & & & & & & \\
\hline \multicolumn{22}{|l|}{ POLYGONACEAE } \\
\hline Coccoloba alnifolia Casar. & D.Araujo 1737 & Ps & & $\bullet$ & & & $\bullet$ & & & & $\bullet$ & & & & & $\bullet$ & & & & & \\
\hline \multicolumn{22}{|l|}{ RUBIACEAE } \\
\hline Amaioua intermedia Mart. ex Roem. \& Schult. & L.F.Menezes 585 & In & & & & & $\bullet$ & $\bullet$ & & & $\bullet$ & & & & $\bullet$ & & $\bullet$ & & $\bullet$ & & \\
\hline Melanopsidium nigrum Cels. & L.F.Menezes 560 & Ps & & & & & & & & & & & & & & & & & & & \\
\hline RUTACEAE & & & & & & & & & & & & & & & & & & & & & \\
\hline Almeidea rubra A. St-Hil. & L.F.Menezes 631 & $\mathrm{Se}$ & & & & & & & & & & & & & & & & & & & \\
\hline Pilocarpus spicatus A.St.-Hil. & D.Araujo 9967 & Ps & & & & & & & & & $\bullet$ & & & & & & & & & & \\
\hline SAPINDACEAE & & & & & & & & & & & & & & & & & & & & & \\
\hline Cupania emarginata Cambess. & D.Araujo 1844 & Ps & & $\bullet$ & & & $\bullet$ & & & & & & & & & $\bullet$ & & & & & \\
\hline Cupania oblongifolia Mart. & D.Araujo 1607 & Ps & & & & & & $\bullet$ & & & $\bullet$ & & & & & & & & & & \\
\hline Matayba intermedia Radlk. & L.F.Menezes 581 & Ps & & & & & & & & & & & & & & & & & & & \\
\hline SAPOTACEAE & & & & & & & & & & & & & & & & & & & & & \\
\hline Manilkara subsericea (Mart.) Dubard & D.Araujo 9974 & Ps & & $\bullet$ & & & $\bullet$ & $\bullet$ & & $\bullet$ & & & $\bullet$ & & & & $\bullet$ & & & & \\
\hline Pouteria caimito (Ruiz \& Pav.) Radlk. & L.F.Menezes 685 & Ps & & & & & $\bullet$ & & & & & & & & & & & & & & \\
\hline URTICACEAE & & & & & & & & & & & & & & & & & & & & & \\
\hline Cecropia glazioui Snethl. & L.F.Menezes 1030 & Ps & & & & & & $\bullet$ & & & $\bullet$ & & & & & & & & & & \\
\hline
\end{tabular}


Estes resultados são semelhantes aos de outros levantamentos de florestas de restinga no sul e sudeste brasileiro, principalmente quanto à presença de Myrtaceae. Tal família é aparentemente característica de solos com baixa fertilidade (Ashton 1988) e já foi mencionada como a que melhor caracteriza a flora dos ambientes de restinga (e.g., Klein 1985, Araujo 2000). Myrtaceae tem sido apontada como a família mais rica em espécies nas florestas de restinga sem inundação no Rio Grande do Sul (Waechter 1990, Waechter et al. 2000), Rio de Janeiro (Assumpção \& Nascimento 2000), São Paulo (César \& Monteiro 1995) e Espírito Santo (Pereira 1990, Pereira et al. 2000, Assis et al. 2004). Em florestas inundáveis de restinga, onde a riqueza específica geralmente é menor, Myrtaceae continua tendo maior riqueza no Rio de Janeiro (R.C. Oliveira, dados não publicados), São Paulo (Suigyama 1998, Sztutman \& Rodrigues 2002) e no Rio Grande do Sul (Waechter \& Jarenkow 1998). Entretanto, no Parque Estadual da Campina do Encantado (SP), na formação onde o substrato é formado por turfeira profunda e permanece inundado praticamente $o$ ano todo, não foram registradas espécies de Myrtaceae (Sztutman \& Rodrigues 2002). É possível que Myrtaceae, além de ser característica de locais com solos pobres, também tolere solos mal drenados por curtos períodos e se aproveite competitivamente do ambiente, conferindo-lhe maior riqueza, porém não suporte a inundação contínua ou prolongada.

A diversidade arbórea estimada pelo Índice de Shannon (H') foi de 2,87 e o índice de equabilidade (J) foi de 0,68. De modo geral, áreas de florestas que sofrem inundação apresentam menor diversidade de espécies em relação a florestais bem drenadas. Isso tem sido atribuído ao caráter seletivo exercido pela inundação no processo de estabelecimento e desenvolvimento das plantas (Crawford 1992, Toniato et al. 1998, Scarano 1998, Scarano et al. 1998). A inundação elimina os espaços de ar do solo limitando as trocas gasosas com a atmosfera e, em poucas horas, as raízes e os microorganismos consomem o oxigênio presente na água, criando um ambiente anóxico ou hipóxico (Lobo \& Joly 2000). Entretanto, quando se compara o valor de diversidade da floresta mal drenada da Marambaia com o de outras florestas litorâneas do sul-sudeste brasileiro (Tab. 3), há tanto florestas não inundáveis com valores menores (e.g. Dillenburg et al. 1992, Waechter et al. 2000), quanto florestas inundáveis com valor de diversidade superior (e.g. Sugiyama 1998 - Área I). Esses resultados indicam que o período, a intensidade ou frequência da inundação não se relacionam de maneira linear com a diversidade ou riqueza de espécies. Isto nos permite lançar a hipótese de que outros fatores podem ter influenciado os índices de diversidade das áreas comparadas, como, por exemplo, a estrutura e composição química dos solos, limitação da distribuição de espécies por condições climáticas das latitudes subtropicais, proximidade com a encosta atlântica, história de intervenção antrópica e a heterogeneidade ambiental das áreas levantadas, já que, quanto maior a variação de ambientes, maior é a diversidade esperada (Guedes et al. 2006). Além disto, as diferenças nos valores de diversidade e riqueza observados entre os estudos listados na tabela 3 são fortemente influenciadas pela variação de métodos empregados em cada estudo, principalmente no que se refere ao critério de inclusão (DAP) e tamanho da amostragem utilizada.

A formação foi caracterizada predominantemente por indivíduos de altura entre cinco e oito metros (Fig. 2A). A média das alturas das árvores foi de $8,5 \mathrm{~m}$ e o dossel da floresta foi estimado a $20 \mathrm{~m}$. Destacaram-se nesse estrato, em virtude do número de indivíduos, as mesmas seis espécies que apareceram com os maiores VI nessa formação (Tab. 4). As espécies mais altas e que compuseram o dossel foram Tapirira guianensis Aubl., Pouteria caimito (Ruiz \& Pav.) Radlk., Matayba intermedia Radlk., Calophyllum brasiliense Cambess., Guapira opposita (Vell.) Reitz, Chaetocarpus myrsinites Baill., Protium brasiliense(Spreng.) Engl., Garcinia brasiliensis Mart., Ocotea notata (Nees) Mez e Pera glabrata (Schott) Baill., sendo a maior altura registrada para um indivíduo de Tapirira guianensis Aubl. e outro de Calophyllum brasiliense Cambess., ambos com $25 \mathrm{~m}$.

Com relação à distribuição dos indivíduos nas diferentes classes de diâmetro, houve maior concentração de árvores na classe de 2,5 a $7,5 \mathrm{~cm}(61,6 \%)$, indicando acentuada presença de elementos arbóreos de diâmetro reduzido nesse ambiente (Fig. 2B). De fato, a configuração do histograma de classes de diâmetro apresenta a forma de "J" invertido, o que sugere a existência de um decréscimo acentuado no número de indivíduos, no sentido das menores para as maiores classes de diâmetro.

Neste estudo, a distribuição de classes de alturas e de diâmetros, foi similar ao registrado em outras formações florestais inundáveis e não inundáveis de restinga no litoral sul e sudeste do Brasil (Dorneles \& Waechter 2004b, Assis et al. 2004). Como em outras formações florestais, o elevado número de indivíduos, nas duas ou três menores classes diamétricas e de altura da floresta da Marambaia, é um importante indicativo sobre a capacidade de renovação da floresta pelo estabelecimento de indivíduos arbóreos de pequeno porte no estrato regenerativo (Whitmore 1982). Entretanto, vale ressaltar que o critério de inclusão utilizado no presente estudo contribuiu para a elevada concentração de indivíduos nas menores classes de diâmetro, especialmente nas duas primeiras.

Nas parcelas estabelecidas foram registrados 1.223 indivíduos vivos. Somou-se a esse valor um total de 76 indivíduos mortos (5,8\% em relação às vivas). A densidade total foi de 2.446 ind.ha $^{-1} \mathrm{e}$ a área basal de $25,14 \mathrm{~m}^{2}$.ha ${ }^{-1}$. Os valores de densidade e área basal encontrados na Marambaia, de maneira geral, quando comparados com outros estudos realizados em florestas de restingas brasileiras (Tab. 3), apresentaram-se superiores ou inferiores a algumas florestas inundáveis ou inundadas. Estas diferenças podem ter ocorrido em função da variação dos métodos empregados em cada trabalho, principalmente quanto ao critério 

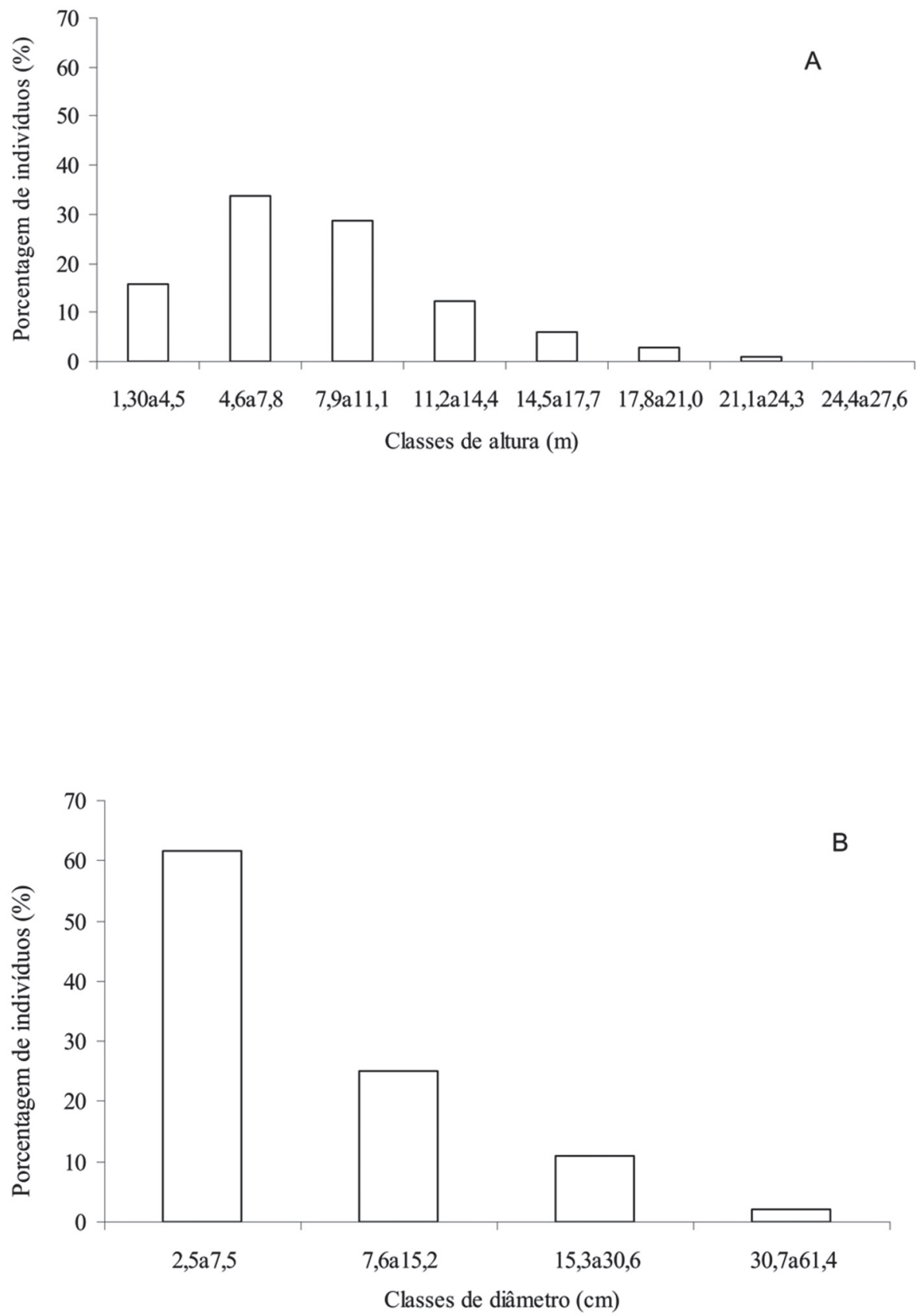

Figura 2. Porcentagem de indivíduos lenhosos observados em diferentes classes de altura (A) e diâmetro (B) na floresta mal drenada na Restinga da Marambaia, RJ, Brasil.

de inclusão (DAP). É possível ainda que estas diferenças reflitam as características estruturais e diversidade de cada uma das áreas, que inclui florestas que sofrem inundações em alguns períodos do ano (Sugyiama 1998, César \& Monteiro 1995). Entretanto, quando comparada com as florestas bem drenadas, com exceção daquela estuda por Assumpção \& Nascimento (2000) em São João da Barra (RJ) que, de fato, incluíram trechos arbustivos na amostragem, os valores de área basal e densidade foram maiores. $\mathrm{O}$ uso de 2,5 cm de DAP como critério mínimo de inclusão na amostragem do presente estudo possibilitou a inclusão de alta densidade de árvores finas, como observado no histograma de classes de diâmetro. Alguns autores relacionam este fato com fatores edáficos, neste caso o alagamento do solo que resulta em respostas fenológicas, morfológicas e fisiológicas diferentes, como a baixa produtividade líquida e, consequentemente, restrição ao desenvolvimento das árvores (Schöngart et al. 2002)

Indivíduos mortos apresentaram área basal de 1,28 $\mathrm{m}^{2}$.ha- $\mathrm{a}^{-1}$ (5\% da área basal total), sendo que $67 \%$ destes encontravam-se na primeira classe de diâmetro e $15 \%$ na segunda. A densidade de mortas obtida (152 ind.ha ${ }^{-1}$ ) é 
Tabela 3. Valores de densidade, área basal, riqueza (Rq.), equabilidade (J') e diversidade (H') de 20 florestas de restinga no Brasil, com diferentes situações de drenagem do solo, avaliadas sob diferentes metodologias e critérios de inclusão dos indivíduos amostrados. Linhas em cinza indicam florestas não inundáveis; linhas em branco indicam florestas inundáveis ou inundadas. É indicada a referência para cada estudo.

\begin{tabular}{|c|c|c|c|c|c|c|c|c|}
\hline Fonte & Estado & Método de análise & $\begin{array}{c}\text { Critério de } \\
\text { inclusão (DAP) }\end{array}$ & $\begin{array}{l}\text { Densidade } \\
\text { ind/há }\end{array}$ & Área basal m².ha-1 & $\mathrm{Rq}$ & $\mathrm{J}^{\prime}$ & $\mathrm{H}^{\prime}$ \\
\hline Assis et al. (2004) & ES & parcela & $4,8 \mathrm{~cm}$ & 2.106 & 27,52 & 92 & 0,83 & 3,73 \\
\hline Assumpção \& Nascimento (2000) & $\mathrm{RJ}$ & parcela & $2,5 \mathrm{~cm}^{*}$ & 4.222 & ------- & 61 & 0,68 & 2,81 \\
\hline R. C. Oliveira (dados não publicados) & $\mathrm{RJ}$ & parcela & $5,0 \mathrm{~cm}$ & 1.876 & 32,95 & 45 & 0,73 & 2,79 \\
\hline M. J. Barros (dados não publicados) & $\mathrm{RJ}$ & parcela & $5,0 \mathrm{~cm}$ & 1.590 & 13,89 & 49 & 0,71 & 2,76 \\
\hline Sá \& Araujo (2009) & $\mathrm{RJ}$ & quadrante & $5,0 \mathrm{~cm}$ & 1.597 & 23,3 & 108 & 0,87 & 4,06 \\
\hline Este estudo & RJ & parcela & $2,5 \mathrm{~cm}$ & 2.446 & 25,14 & 57 & 0,68 & 2,87 \\
\hline Sugiyama (1998) - Área I & SP & parcela & $2,5 \mathrm{~cm}$ & 4.652 & 27,36 & 56 & 0,77 & 3,09 \\
\hline Sugiyama (1998) - Área II & SP & parcela & $1,6 \mathrm{~cm}$ & 8.670 & 23,25 & 31 & 0,71 & 2,44 \\
\hline Guedes et al. (2006) Área I & SP & parcela & $3,2 \mathrm{~cm}$ & 1.983 & 26,64 & 65 & 0,84 & 3,5 \\
\hline Guedes et al. (2006) Área II & SP & parcela & $3,2 \mathrm{~cm}$ & 1.737 & 27,69 & 67 & 0,89 & 3,7 \\
\hline César \& Monteiro (1995) & $\mathrm{SP}$ & parcela & $5,0 \mathrm{~cm}$ & 1.915 & 12,56 & 73 & 0,8 & 3,48 \\
\hline Sztutman \& Rodrigues (2002) (turfeira rasa) & SP & parcela & $4,8 \mathrm{~cm}$ & 1.730 & 27,7 & 46 & 0,78 & 2,98 \\
\hline Sztutman \& Rodrigues (2002) (turfeira profunda) & SP & parcela & $4,8 \mathrm{~cm}$ & 2.730 & 19,2 & 5 & 0,51 & 0,82 \\
\hline Silva et al. (1994) & PR & parcela & $5,0 \mathrm{~cm}$ & 2.763 & 46,46 & 53 & 0,81 & 3,22 \\
\hline Dorneles \& Waechter (2004a) & RS & quadrante & $5,0 \mathrm{~cm}$ & 1.031 & 9,7 & 27 & 0,8 & 2,65 \\
\hline Dorneles \& Waechter (2004b) & RS & quadrante & $5,0 \mathrm{~cm}$ & 3.479 & ------ & 21 & 0,85 & 2,6 \\
\hline Scherer et al. (2005) & RS & parcela & $5,0 \mathrm{~cm}$ & $1.023 * *$ & ------ & 31 & $0,69 * *$ & $1,98^{* *}$ \\
\hline Waechter \& Jarenkow (1998) & RS & quadrante & $10,0 \mathrm{~cm}$ & 791 & ------ & 12 & 0,79 & 1,89 \\
\hline Waechter et al. (2000) & $\mathrm{RS}$ & quadrante & $10,0 \mathrm{~cm}$ & 834 & ------ & 24 & 0,76 & 2,41 \\
\hline Dillenburg et al. (1992) & RS & quadrante & $5,0 \mathrm{~cm}$ & 2.219 & 4,37 & 15 & 0,73 & 1,98 \\
\hline
\end{tabular}

* diâmetro a altura do solo $\quad * *$ valores médios de cinco áreas

superior a encontrada em florestas com solos bem drenados em Santa Catarina - 66 ind.ha ${ }^{-1}$ (Silva et al. 1994), Espírito Santo - 67 ind.ha $^{-1}$ (Assis et al. 2004), Rio de Janeiro - 120 ind.ha ${ }^{-1}$ (Lobão \& Kurtz 2000). Considerando que os maiores contingentes de indivíduos mortos foram observados nas primeiras classes de diâmetros, o que melhor explicaria a mortalidade de árvores na Marambaia seria o processo natural de senescência devido a competitividade por luz, já que são nestes estratos onde o recurso luz é mais limitado devido ao sombreamento pelas árvores de maior porte (Franklin et al. 1987).

Dez espécies apresentaram VI acima de nove, correspondendo o somatório de seus valores a 75\% do VI total (Tab. 4). As espécies com maiores valores de VI foram Tapirira guianensis Aubl. (42,42), Amaioua intermedia Mart. ex Roem. \& Schult. $(40,77)$ e Chaetocarpus myrsinites Baill. $(39,98)$, que juntas detiveram $41 \%$ do VI total, evidenciando o destaque que essas espécies possuem na estrutura da floresta. A maior importância de Tapirira guianensis Aubl., em relação às outras espécies, foi devido ao seu desenvolvimento estrutural, com alto valor de área basal, o que lhe atribuiu dominância relativa alta. Valores de dominância relativa também foram responsáveis pelos altos VIs em Chaetocarpus myrsinites Baill., Protium brasiliense (Spreng.) Engl. e Pouteria caimito (Ruiz \& Pav.) Radlk.; enquanto que a importância de Amaioua intermedia Mart. ex Roem. \& Schult., Eugenia sulcata Spreng. ex Mart. e Garcinia brasiliensis Mart. diz respeito ao número elevado de indivíduos dessas espécies, correspondendo à densidades relativas altas. Essas três espécies foram responsáveis pela concentração de $40 \%$ do total de indivíduos amostrados. De fato, a concentração de abundâncias em poucas espécies é mais pronunciada em solos mal drenados e com maior fertilidade, quando comparado com os estudos em florestas bem drenadas (e.g. Assis et al. 2004). Nesse sentido, Amaioua intermedia Mart. ex Roem. \& Schult. apresentou destaque em algumas florestas inundáveis aqui comparadas, com maior valor de VI na floresta de restinga em Iguape (SP) (M. B. Ramos-Neto, dados não publicados), e a segunda de maior VI na floresta inundável em Bertioga (SP) (Guedes et al. 2006). A grande maioria das espécies ocorreu em baixas frequências sendo que 19 espécies (33,3\%) estiveram presentes em menos de $40 \%$ das parcelas. 
Tabela 4. Descritores fitossociológicos das espécies da floresta mal drenada na Restinga da Marambaia, RJ, Brasil. N= Número de indivíduos amostrados; DA= Densidade Absoluta $\left(\mathrm{N} \cdot \mathrm{ha}^{-1}\right)$; DR = Densidade Relativa; DoA = Dominância Absoluta $\left(\mathrm{m}^{2} \cdot \mathrm{ha}^{-1}\right)$; DoR $=$ Dominância Relativa; FA = Freqüência Absoluta; FR = Freqüência Relativa; VI = valor de Importância

\begin{tabular}{|c|c|c|c|c|c|c|c|c|}
\hline ESPÉCIE & $\mathrm{N}$ & DA & DR & DoA & DoR & FA & FR & VI \\
\hline Tapirira guianensis & 92 & 184 & 7,52 & 13,70 & 27,25 & 88 & 7,65 & 42,42 \\
\hline Amaioua intermedia & 284 & 568 & 23,22 & 4,89 & 9,72 & 90 & 7,83 & 40,77 \\
\hline Chaetocarpus myrsinites & 93 & 186 & 7,60 & 8,15 & 16,21 & 186 & 16,17 & 39,98 \\
\hline Eugenia sulcata & 101 & 202 & 8,26 & 2,43 & 4,82 & 66 & 5,74 & 18,82 \\
\hline Protium brasiliense & 87 & 174 & 7,11 & 3,09 & 6,15 & 62 & 5,39 & 18,65 \\
\hline Garcinia brasiliensis & 115 & 230 & 9,40 & 2,23 & 4,44 & 50 & 4,35 & 18,19 \\
\hline Pouteria caimito & 56 & 112 & 4,58 & 3,22 & 6,41 & 66 & 5,74 & 16,73 \\
\hline Myrcia acuminatissima & 62 & 124 & 5,07 & 0,35 & 0,70 & 64 & 5,57 & 11,33 \\
\hline Gomidesia martiana & 53 & 106 & 4,33 & 0,78 & 1,55 & 54 & 4,70 & 10,58 \\
\hline Guapira opposita & 29 & 58 & 2,37 & 1,73 & 3,45 & 42 & 3,65 & 9,47 \\
\hline Couepia schottii & 25 & 50 & 2,04 & 1,34 & 2,66 & 38 & 3,30 & 8,01 \\
\hline Matayba intermedia & 17 & 34 & 1,39 & 1,47 & 2,93 & 28 & 2,43 & 6,76 \\
\hline Andira fraxinifolia & 17 & 34 & 1,39 & 0,71 & 1,40 & 30 & 2,61 & 5,40 \\
\hline Aspidosperma parvifolium & 16 & 32 & 1,31 & 0,83 & 1,64 & 24 & 2,09 & 5,04 \\
\hline Myrcia recurvata & 18 & 36 & 1,47 & 0,58 & 1,16 & 26 & 2,26 & 4,89 \\
\hline Ocotea notata & 11 & 22 & 0,90 & 1,02 & 2,04 & 14 & 1,22 & 4,15 \\
\hline Cupania emarginata & 13 & 26 & 1,06 & 0,35 & 0,69 & 22 & 1,91 & 3,66 \\
\hline Eugenia punicifolia & 11 & 22 & 0,90 & 0,15 & 0,30 & 18 & 1,57 & 2,76 \\
\hline Pera glabrata & 8 & 16 & 0,65 & 0,39 & 0,78 & 14 & 1,22 & 2,65 \\
\hline Actinostemon communis & 9 & 18 & 0,74 & 0,14 & 0,28 & 16 & 1,39 & 2,41 \\
\hline Eugenia bahiensis & 13 & 26 & 1,06 & 0,12 & 0,23 & 10 & 0,87 & 2,16 \\
\hline Pilocarpus spicatus & 12 & 24 & 0,98 & 0,23 & 0,46 & 8 & 0,70 & 2,14 \\
\hline Syagrus romanzoffiana & 3 & 6 & 0,25 & 0,42 & 0,84 & 6 & 0,52 & 1,61 \\
\hline Myrcia multiflora & 7 & 14 & 0,57 & 0,16 & 0,32 & 8 & 0,70 & 1,59 \\
\hline Ocotea pulchella & 3 & 6 & 0,25 & 0,36 & 0,71 & 6 & 0,52 & 1,48 \\
\hline Calyptranthes brasiliensis & 6 & 12 & 0,49 & 0,05 & 0,11 & 10 & 0,87 & 1,47 \\
\hline Miconia cinnamomifolia & 7 & 14 & 0,57 & 0,05 & 0,10 & 8 & 0,70 & 1,36 \\
\hline Calophyllum brasiliense & 2 & 4 & 0,16 & 0,34 & 0,68 & 4 & 0,35 & 1,19 \\
\hline Eugenia rostrata & 4 & 8 & 0,33 & 0,07 & 0,14 & 8 & 0,70 & 1,16 \\
\hline Cupania oblongifolia & 3 & 6 & 0,25 & 0,14 & 0,28 & 6 & 0,52 & 1,04 \\
\hline Gomidesia fenzliana & 4 & 8 & 0,33 & 0,03 & 0,05 & 6 & 0,52 & 0,90 \\
\hline Andira legalis & 4 & 8 & 0,33 & 0,09 & 0,17 & 4 & 0,35 & 0,85 \\
\hline Coccoloba alnifolia & 3 & 6 & 0,25 & 0,02 & 0,04 & 6 & 0,52 & 0,81 \\
\hline Myrsine parvifolia & 1 & 2 & 0,08 & 0,26 & 0,52 & 2 & 0,17 & 0,78 \\
\hline Xylopia ochrantha & 2 & 4 & 0,16 & 0,02 & 0,04 & 6 & 0,52 & 0,73 \\
\hline Ouratea cuspidata & 2 & 4 & 0,16 & 0,04 & 0,08 & 4 & 0,35 & 0,59 \\
\hline Ormosia arbórea & 2 & 4 & 0,16 & 0,10 & 0,21 & 2 & 0,17 & 0,54 \\
\hline Myrciaria floribunda & 2 & 4 & 0,16 & 0,02 & 0,04 & 4 & 0,35 & 0,55 \\
\hline Sloanea guianensis & 2 & 4 & 0,16 & 0,02 & 0,03 & 4 & 0,35 & 0,54 \\
\hline Manilkara subsericea & 2 & 4 & 0,16 & 0,01 & 0,02 & 4 & 0,35 & 0,53 \\
\hline Eugenia brasiliensis & 2 & 4 & 0,16 & 0,01 & 0,01 & 4 & 0,35 & 0,53 \\
\hline Cybianthus sp. nova & 3 & 6 & 0,25 & 0,01 & 0,03 & 2 & 0,17 & 0,44 \\
\hline Myrsine venosa & 2 & 4 & 0,16 & 0,01 & 0,03 & 2 & 0,17 & 0,36 \\
\hline
\end{tabular}


Tabela 4. Continuação.

\begin{tabular}{|c|c|c|c|c|c|c|c|c|}
\hline ESPÉCIE & $\mathrm{N}$ & DA & DR & DoA & DoR & FA & FR & VI \\
\hline Ilex integerrima & 2 & 4 & 0,16 & 0,00 & 0,01 & 2 & 0,17 & 0,35 \\
\hline Melanopsidium nigrum & 1 & 2 & 0,08 & 0,03 & 0,06 & 2 & 0,17 & 0,32 \\
\hline Myrcia lundiana & 1 & 2 & 0,08 & 0,02 & 0,04 & 2 & 0,17 & 0,30 \\
\hline Alchornea triplinervia & 1 & 2 & 0,08 & 0,02 & 0,04 & 2 & 0,17 & 0,29 \\
\hline Myrsine guianensis & 1 & 2 & 0,08 & 0,02 & 0,03 & 2 & 0,17 & 0,29 \\
\hline Annona glabra & 1 & 2 & 0,08 & 0,01 & 0,02 & 2 & 0,17 & 0,28 \\
\hline Inga laurina & 1 & 2 & 0,08 & 0,01 & 0,02 & 2 & 0,17 & 0,28 \\
\hline Cecropia glazioui & 1 & 2 & 0,08 & 0,01 & 0,02 & 2 & 0,17 & 0,27 \\
\hline Anaxagorea dolichocarpa & 1 & 2 & 0,08 & 0,01 & 0,01 & 2 & 0,17 & 0,27 \\
\hline Pseudopiptadenia contorta & 1 & 2 & 0,08 & 0,00 & 0,01 & 2 & 0,17 & 0,26 \\
\hline Almeidea rubra & 1 & 2 & 0,08 & 0,00 & 0,01 & 2 & 0,17 & 0,26 \\
\hline Ouratea miersii & 1 & 2 & 0,08 & 0,00 & 0,01 & 2 & 0,17 & 0,26 \\
\hline Xylopia sericea & 1 & 2 & 0,08 & 0,00 & 0,01 & 2 & 0,17 & 0,26 \\
\hline Maytenus robusta & 1 & 2 & 0,08 & 0,00 & 0,00 & 2 & 0,17 & 0,26 \\
\hline Totais & 1223 & 2446 & 100 & 50,27 & 100 & 1150 & 100 & 300 \\
\hline
\end{tabular}

A distribuição dos VIs encontrado nesse estudo, onde um maior percentual desse índice encontra-se em poucas espécies, enquanto a maior parte das outras apresentam baixos valores, tem sido frequentemente encontrado para diversas formações florestais tropicais onde às condições ambientais são mais severas (Ivanauskas \& Rodrigues 2000, Moreno et al. 2003, Assis et al. 2004). Isso nos leva a crer que a magnitude da oligarquia de espécies de acordo com o VI, pode ser interpretada como consequência do estresse ao qual a formação está submetida. Em ambientes marcados por condições ambientais extremas, como baixa disponibilidade de água e nutrientes ou excesso de água e nutrientes, tendem a aumentar a dominância ecológica de algumas espécies (Scarano 2000, Scarano 2002). Esta hipótese é corroborada quando comparamos os valores de equabilidade das florestas bem drenadas listadas na Tabela 3 com o valor encontrado para a floresta da Marambaia, que indica uma tendência de distribuição menos homogênea da abundância entre as espécies.

Analisando a espécie de maior VI nesse estudo, nota-se que Tapirira guianensis Aubl. também obteve esta posição na floresta de restinga inundável do Parque Nacional de Jurubatiba (RJ), com 16,7\% do VI total (R.C. Oliveira, dados não publicados) e no Parque Estadual da Campina do Encantado (SP), com $21,1 \%$ do VI total (Sztutman \& Rodrigues 2002). Esse fato pode ser, assim como neste estudo, atribuído aos expressivos valores de dominância, frequência e densidade relativas desta espécie nestas áreas. Em outras formações vegetais de restinga que não sofrem inundação do solo, essa espécie também aparece algumas vezes entre aquelas de maior VI (Klein 1990), indicando sua tolerância à solos mal drenados.

A maior similaridade da floresta mal drenada da Marambaia foi observada com as florestas inundáveis inventariadas no Parque Nacional de Jurubatiba (RJ) - 23,8\% (R.C. Oliveira, dados não publicados) e 21,4\% (M.J. Barros, dados não publicados) (Fig. 3). Baixas similaridades florísticas foram encontras com as florestas do Rio Grande do Sul, tanto a inundável, quanto aquelas sobre solos bem drenados. Entretanto, a menor similaridade foi constatada com a floresta sobre uma turfeira profunda, em São Paulo (1,6\%).

A análise do dendograma permitiu a distinção de quatro grupos formados por áreas que se ligam por suas similaridades florísticas. O primeiro foi formado pelas florestas do Rio Grande do Sul (áreas 1, 3, 4, 7, 16 e 19), sendo que as bem drenadas se assemelham mais entre si (áreas 1, 3, 4, e 7) do que as inundáveis (áreas 16 e 19); o segundo pelas florestas bem drenadas do norte do Rio de Janeiro e sul do Espírito Santo (áreas 2, 5 e 8); o terceiro pelas florestas do Rio de Janeiro, São Paulo e Paraná (áreas 6, 10, 11, 12, 13, 1415,17 e 20), sendo que, com exceção da área 6 , todas são inundáveis. Vale ressaltar que neste caso, mesmo descrita como não inundável, o trecho florestal em Bertioga que corresponde a área 6 (Guedes et al. 2006), apresenta espécies exclusivas (e.g. Tabebuia cassinoides DC.) e seletivas (e.g. Calophyllum brasiliense Cambess.) de áreas inundáveis. Isto nos leva a crer que, mesmo não sendo evidente o afloramento do lençol freático, a floresta de Bertioga apresenta um padrão de inundação semelhante ao da Marambaia, onde a zona das raízes sofre com o alagamento. $\mathrm{O}$ quarto grupo foi formado pela floresta de turfeira profunda em São Paulo (área 18), que destacou sua acentuada dissimilaridade com as demais florestas.

Dentro do grupo formado pelas florestas do Rio de Janeiro, São Paulo e Paraná observam-se subgrupos, constituídos pelas florestas inundáveis do Rio de Janeiro, juntamente com a mal drenada do presente estudo (áreas 13, 14 e 20) 


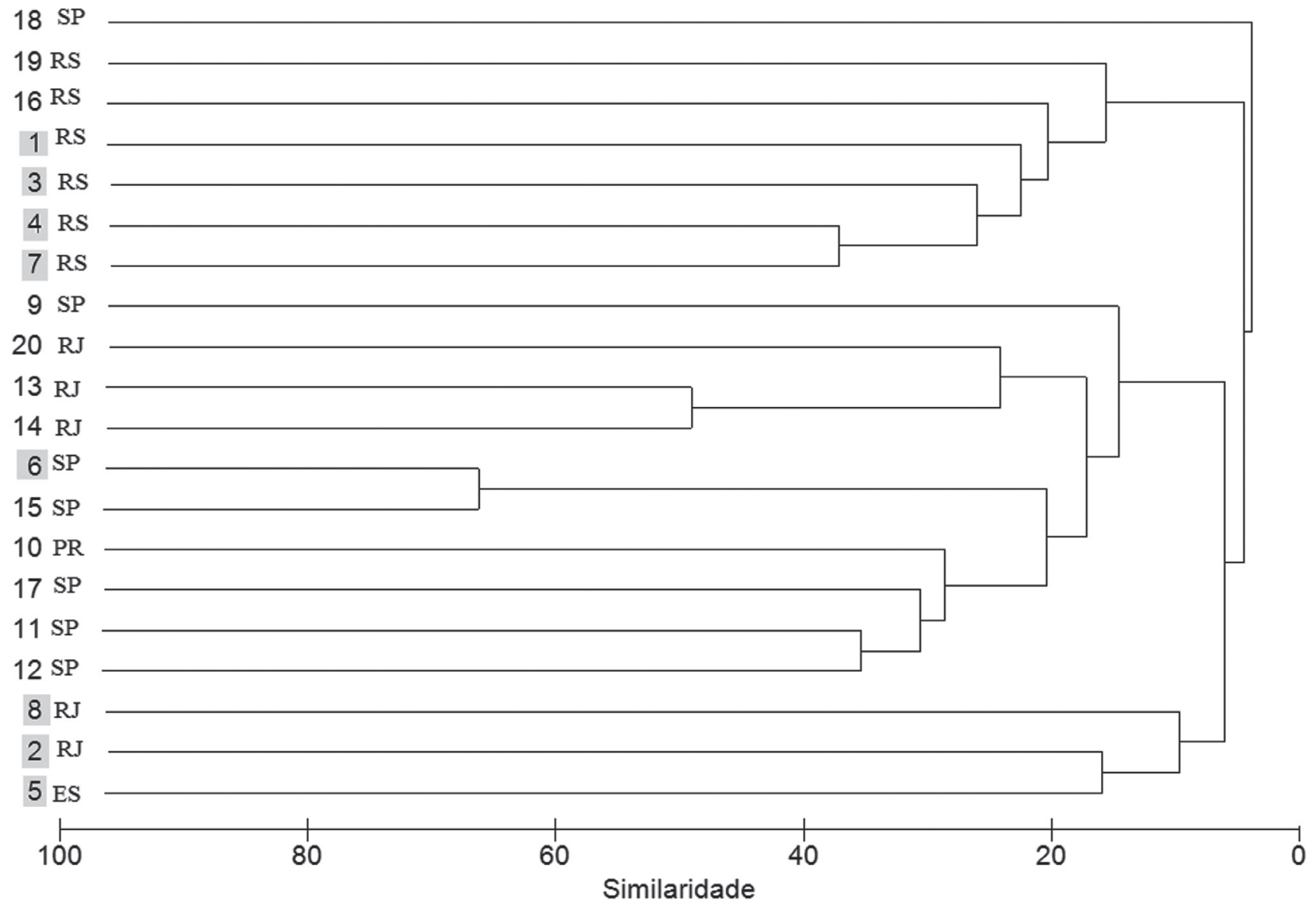

Figura 3. Análise de agrupamento entre 20 florestas de restinga do sul e sudeste brasileiro, por meio de ligação por média aritmética (UPGMA), usando o coeficiente de Jaccard como medida de similaridade. A numeração indica a referência bibliográfica, especificada na metodologia. Números em cinza indicam florestas não inundáveis.

e pelas florestas de São Paulo e Paraná $(6,10,11,12,15$ e 17). A floresta inundável de Picinguaba (SP) (9) ficou isolada, assemelhando-se com as florestas inundáveis do Rio de Janeiro e com as florestas inundáveis e não inundáveis de São Paulo e Paraná.

Dessa forma, a análise de agrupamento demonstrou maior relação entre a composição florística com a proximidade geográfica das áreas analisadas e secundariamente com a intensidade de inundação que caracteriza cada uma delas. Assim, as florestas inundáveis do Rio de Janeiro, juntamente com a mal drenada da Marambaia, formaram um subgrupo que excluiu as florestas inundáveis dos outros estados (São Paulo, Paraná e Rio Grande do Sul) e as florestas inundáveis e não inundáveis do Rio Grande do Sul também formaram um subgrupo relativamente coeso.

O grupo constituído pelas florestas bem drenadas do sul do Espírito Santo e norte do Rio de Janeiro demonstrou maior compartilhamento de espécies que se restringem às áreas sem inundação e que não se distribuem para o sul, além do estado do Rio de Janeiro, pelo menos na zona litorânea. Além disso, o grupo formado pelas florestas inundáveis do Rio de Janeiro demonstrou que a floresta da Marambaia tem ligações florísticas mais fortes com as florestas do norte desse estado, do que com aquelas mais ao sul. Essas ligações mais fortes das restingas fluminenses com a flora costeira mais ao norte do país já foi demonstrado por Araujo (2000), e também por Nascimento \& Lima (2008), para as florestas de tabuleiro do nordeste do estado.

As florestas inundáveis de São Paulo e Paraná constituíram um subgrupo pouco similar com aquele formado pelas florestas do Rio de Janeiro, mas que, em conjunto, apresentam dissimilaridade ainda maior com as florestas bem drenadas do Espírito Santo e norte do Rio de Janeiro e com aquelas do sul do país. Esse grupo maior, formado exclusivamente por florestas inundáveis dos estados do Rio de Janeiro, São Paulo e Paraná teve sua similaridade atribuída à presença de Andira fraxinifolia Benth., Guapira opposita (Vell.) Reitz, Alchornea triplinervia (Spreng.) Müll. Arg., Pera glabrata (Schott) Baill., Calophyllum brasiliense Cambess., Psidium cattleyanum Sabine, Ocotea pulchella (Nees) Mez e Myrcia multiflora (Lam.) DC., que apresentam ampla distribuição nas restingas (Tab. 2), fato já observado por Guedes et al. (2006).

Segundo tais circunstâncias é razoável concluir que não existe uma flora particular para as formações inundáveis nas restingas do sul e sudeste brasileiro e que mudanças no 
padrão florístico da vegetação dessas áreas podem ocorrer em função da proximidade da fonte de propágulos de espécies com alta tolerância à inundação do solo e também em função de questões fitogeográficas, onde algumas espécies parecem ser limitadas por condições climáticas das latitudes subtropicais (Oliveira-Filho \& Ratter 2000).

Amplitude ecológica das espécies - A formação florestal analisada foi composta principalmente por espécies preferenciais de áreas bem drenadas, ou seja, espécies com preferência por inundação periódica do solo ou solos bem drenados, mas não por inundação permanente ou quase permanente do solo (Tab. 2). Das 60 espécies listadas para a formação, 36 pertenciam a essa categoria $(60 \%)$. Espécies seletivas representaram 21,7\% (13 espécies). Espécies indiferentes representaram $18,3 \%$ (11 espécies) e não houve registro de espécies exclusivas de áreas inundadas. Nossa hipótese para a presença de $60 \%$ de espécies consideradas preferenciais de áreas bem drenadas na formação estudada é de que a frequência e intensidade da inundação do solo são pouco seletivas, o que permitiu o estabelecimento de espécies típicas de formações vegetais com solos bem drenados. Isso sugere uma tolerância ecológica de algumas espécies à inundação do solo por curtos períodos, o que contribuiu para aumentar a diversidade da área. Este é o caso, por exemplo, de Pera glabrata (Schott) Baill., Eugenia sulcata Spreng. ex Mart., Myrcia acuminatissima O. Berg., Psidium cattleyanum Sabine e Guapira opposita (Vell.) Reitz, citadas para florestas bem drenadas (Assumpção \& Nascimento 2000, Assis et al. 2004), mas também citadas para florestas inundáveis (Silva et al.1994, Sugiyama 1998, Waechter \& Jarenkow 1998 e Dorneles \& Waechter 2004a). Isso explica, em parte, a maior riqueza de espécies na Marambaia, em relação a outras florestas de restinga inundáveis analisadas neste estudo.

A ausência de espécies exclusivas de áreas inundadas, comuns em outras formações vegetais na Marambaia (e.g. Tabebuia cassinoides DC.), foi um indicativo de que a formação estudada não sofre com alta intensidade e frequência do encharcamento do solo. Por outro lado, essa condição foi suficiente para proporcionar a presença de espécies seletivas (e.g. Calophyllum brasiliense Cambess., Hedyosmum brasiliense Mart., Sloanea guianensis (Aubl.) Benth., Alchornea triplinervia (Spreng.) Müll.Arg., Andira fraxinifolia Benth., Myrsine venosa A. DC., entre outras). Tais espécies também estiveram presentes em um trecho de floresta de restinga em Bertioga (SP), considerado por Guedes et al. (2006) como não sujeito a alagamento prolongado.

No presente estudo, Calophyllum brasiliense Cambess. não foi considerada espécie exclusiva de áreas inundadas devido ao fato de não haver registro de sua ocorrência neste tipo florestal em restinga. C. brasiliense é uma espécie capaz de germinar após vários meses de submersão (embora enquanto inundadas as sementes não germinem) e cujas plântulas crescem normalmente, tanto em solo inundado quanto drenado. Desvantagens competitivas podem explicar a ausência dessa espécie em florestas bem drenadas, apesar de crescer bem quando cultivada em condições de boa drenagem (Lobo \& Joly 2000).

As espécies aqui consideradas como indiferentes (e.g. Tapirira guianensis DC., Aspidosperma parvifolium A.DC., Protium brasiliense (Spreng.) Engl., Garcinia brasiliensis Mart., Ocotea notata (Nees) Mez, Guapira opposita (Vell.) Reitz, Couepia schottii Fritsch, Gomidesia fenzliana Berg, Amaioua intermedia Mart. ex Roem. \& Schult. e Pera glabrata (Schott) Baill.) foram também citadas para vários tipos de formações vegetais de restinga no litoral brasileiro (Pereira 1990, Silva et al. 1994, Araujo et al. 1998, Pereira \& Araujo 2000, Assis et al. 2004) e parecem tolerar a saturação hídrica por ocorrerem também em ambientes que sofrem inundação do solo. Tapirira guianensis DC., por exemplo, tem ampla distribuição nos neotrópicos, podendo ocorrer em vários tipos de habitats e formações florestais. Além disso, é reconhecidamente tolerante a ambientes sob condições estressantes causadas pela inundação do solo, tendo sido amostrada em $48 \%$ do total de 43 levantamentos florísticos e fitossociológicos de florestas ciliares do Brasil extra-amazônico (Oliveira-Filho \& Ratter 2000).

Em síntese, este estudo inclui na categoria de florestas inundáveis de restinga as florestas que temporariamente têm a zona das raízes submetida à inundação, mesmo que estejam em localidades onde não ocorra o afloramento do lençol freático. A não existência de uma flora particular para as formações inundáveis nas restingas do sul e sudeste brasileiro parece estar relacionada à falta de um padrão florístico da vegetação dessas áreas, principalmente em função da proximidade da fonte de propágulos de espécies com alta tolerância à inundação do solo. Dada a natureza complexa das relações ecológicas que determinam os padrões fitogeográficos, sugerem-se estudos onde sejam identificadas e quantificadas as relações entre espécies vegetais e variáveis ambientais (e.g. climáticas e edáficas) em outros trechos do litoral sudeste brasileiro, gerando maior entendimento das variações florísticas de florestas inundáveis de restinga.

\section{Agradecimentos}

Ao Marcelo da Costa Souza, pelo auxílio nas diversas fases deste estudo; ao Marco Gervasio Pereira, pelo auxílio nas análises de solos; aos pesquisadores que gentilmente identificaram materiais botânicos: Alexandre Quinet, Fernando Regis Di Maio, Genise Vieira Somner, Haroldo Cavalcante de Lima, Maria de Fátima Freitas e Marilena Menezes da Silva Conde; ao Centro de Adestramento da Ilha da Marambaia, pelo apoio e concessão para a realização deste estudo; à CAPES pela concessão de bolsa de doutorado ao primeiro autor.

\section{Referências bibliográficas}

Almeida Jr. E.B.; Olivo, M.A.; Araújo, E.L. \& Zickel, C.S. 2009. caracterizaçao da vegetaçao de restinga da RPPN de Maracaípe, PE, Brasil, com base na fisionomia, flora nutrients do solo e lençol freático. Acta Botanica Brasilica 23(1): 36-48.

APG II. 2003. An update of the Angiosperm Phylogeny Group classification for the orders and families of flowering plants: APG II. Botanical Journal of the Linnean Society 141: 399-436. 
Araujo, D.S.D. \& Henriques, R.P.B. 1984. Análise florística das restingas do estado do Rio de Janeiro. Pp.159-193. In: L.D. Lacerda, D.S.D. Araujo, R. Cerqueira \& B. Turcq (orgs.). Restingas: Origem, Estrutura, Processos. Niterói, CEUFF.

Araujo, D.S.D. 2000. Analise florística e fitogeográfica das restingas do estado do Rio de Janeiro. Tese de doutorado. PPGE-UFRJ.

Araujo, D.S.D.; Scarano, F.R.; Sá, C.F.C.; Kurtz, B.C.; Zaluar, H.L.T.; Montezuma, R.C.M. \& Oliveira, R.C. 1998. Comunidades vegetais do Parque Nacional da Restinga de Jurubatiba. Pp. 39-62. In: F. A. Esteves (ed.). Ecologia das lagoas costeiras do Parque Nacional da Restinga de Jurubatiba e do Município de Macaé (RJ). Rio de Janeiro, NUPEM-UFRJ.

Ashton, P.S. 1988. Systematics and ecology of rain forest trees. Taxon 37(3): 622-629.

Assis, A.M.; Pereira, O.J. \& Thomaz, L.D. 2004. Fitossociologia de uma floresta de restinga no Parque Estadual Paulo César Vinha, Setiba, município de Guarapari (ES). Revista Brasileira de Botânica 27(2): 349-361.

Assumpção, J. \& Nascimento, M.T. 2000. Estrutura e composição florística de quatro formações vegetais de restinga no complexo lagunar Grussaí/ Iquipari, São João da Barra, RJ, Brasil. Acta Botanica Brasilica 14(3): 301-315

Brower, J.E. \& Zar, J.H. 1984. Field \& laboratory methods for general ecology. W.C. Brown Publishers, Boston.

Brummitt, R.K. \& Powell, C.E. 1992. Authors of plant names. Kew, Royal Botanic Garden.

Carvalho, F.A., Nascimento, M.T., Braga, J.M.A. \& Rodrigues, P.J.F. 2006. Estrutura da comunidade arbórea da floresta atlântica de baixada periodicamente inundada na Reserva Biológica de Poço das Antas, Rio de Janeiro, Brasil. Rodriguésia 57(3): 503-518.

César, O. \& Monteiro, R. 1995. Florística e fitossociologia de uma floresta de restinga em Picinguaba (Parque Estadual da Serra do Mar), Município de Ubatuba, SP. Naturalia 20: 89-105.

Crawford, R.M.M. 1992. Oxygen availability as an ecological limit to plant distribution. Advances in Ecological Research 23: 93-185.

Dillenburg, L.R., Waechter, J.L. \& Porto, M.L. 1992. Species composition and structure of a sandy coastal plain forest in northern Rio Grande do Sul, Brazil. Pp. 349-366. In: U. Seeliger (org.). Coastal plant communities of Latin America. New York, Academic Press.

Dorneles, L.P.P. \& Waechter, J.L. 2004a. Fitossociologia do componente arbóreo na floresta turfosa do Parque Nacional da Lagoa do Peixe, Rio Grande do Sul, Brasil. Acta Botanica Brasilica 18(4): 815-824

Dorneles, L.P.P. \& Waechter, J.L. 2004b. Estrutura do componente arbóreo da floresta arenosa de restinga do Parque Nacional da Lagoa do Peixe, Rio Grande do Sul. Hoehnea 31(1):61-71.

EMBRAPA/CNPS. 1997. Manual de métodos de análises de solo. Brasília, EMBRAPA.

Ferreira, L.V. \& Stohlgren, T.J. 1999. Effects of river level fluctuation on plant species richness, diversity, and distribution in a floodplain forest in Central Amazonia. Oecologia 120(4): 582-587.

Fidalgo, O. \& Bononi, V.L.R. 1984. Técnicas de coleta, preservação e herborização de material botânico. São Paulo. Instituto de Botânica. (Manual 4).

Franklin, J.F., Shugart, H.H. \& Harmon, M.E. 1987. Tree death as an ecological process. BioScience 37: 550-556.

Gomes, B.Z.; Martins, F.R. \& Tamashiro, J.Y. 2004. Estrutura do cerradão e da transição entre cerradão e floresta paludícula num fragmento da International Paper do Brasil Ltda. em Brotas, SP. Revista Brasileira de Botânica 27(2): 249-262.

Guedes, D.; Barbosa, L.M. \& Martins, S.E. 2006. Composição florística e estrutura fitossociológica de dois fragmentos de floresta de restinga no Município de Bertioga, SP, Brasil. Acta Botanica Brasilica 20(2): 299-311.

Hay, J.D. \& Lacerda, L.D. 1984. Ciclagem de nutrientes no ecossistema de restinga. Pp. 459-475. In: L.D. Lacerda; D.S.D. Araujo; R. Cerqueira \& B.Turcq (eds). Restingas: Origem, Estrutura, Processos. Niterói, CEUFF

Hubbell, S.P. 2001. The unified neutral theory of Biodiversity and Biogeography Oxford, Princeton University Press.
Ivanauskas, N.M. \& Rodrigues, R.R. 2000. Florística e fitossociologia de remanescentes de floresta estacional decidual em Piracicaba, São Paulo, Brasil. Revista Brasileira de Botânica 23(3): 291-304.

Ivanauskas, N.M.; Rodrigues, R.R. \& Nave, A.G. 1997. Aspectos ecológicos de um trecho de floresta em Itatinga, SP: florística, fitossociologia e seletividade de espécies. Revista Brasileira de Botânica 20: 139-153.

Klein, R.M. 1985. Síntese ecológica da floresta estacional da bacia do Jucuí e importância do reflorestamento com essências nativas (RS). Comunicações do Museu de Ciências PUCRS, Série Botânica 32: 25-48.

Klein, R.M. 1990. Estrutura, composição florística, dinamismo e manejo da "mata atlântica" (floresta ombrófila densa) do sul do Brasil. Pp. 259-286. In: Anais do II Simpósio de ecossistemas da costa sul e sudeste brasileira: estrutura, função e manejo. Águas de Lindóia, 1990. São Paulo, ACIESP. v.1.

Köppen, W. 1948. Climatologia. México, Ed. Fondo Cultura Economica.

Lacerda, L.D.; Araujo, D.S.D. \& Maciel, N.C. 1993. Dry coastal ecosystems of the tropical Brazilian coast. Pp. 477-493. In: van der Maarel, E. (ed.). Dry coastal ecosystems: Africa, America, Asia and Oceania. Amsterdam, Elsevier.

Lobão, A.Q. \& Kurtz, B.C. 2000. Fitossociologia de um trecho de mata atlântica de restinga na praia Gorda, Município de Armação de Búzios, RJ. p.66-73.In. Anais do V Simpósio de Ecossistemas Brasileiro: Conservação. ACIESP, V.3. Vitória.

Lobo, P.C. \& Joly, C.A. 2000. Aspectos ecofisiológicos da vegetação de mata ciliar do sudeste do Brasil. Pp. 143-167. In: R.R. Rodrigues \& H.F. Leitão Filho (eds). Matas ciliares: conservação e recuperação. São Paulo, Universidade de São Paulo.

Magurran, A.E. 1988. Ecological diversity and its measurement. Princeton, Princeton University Press.

Magurran, A.E. 2004. Measuring biological diversity. Oxford, Blackwell Publishing Company, 256p.

Mattos, C. L. 2005. Caracterização climática da Marambaia, RJ. Pp. 55-66. In: L.F.T. Menezes; A.L. Peixoto \& D.S.D. Araujo. História Natural da Marambaia. Seropédica, EDUR.

Menezes, L.F.T. \& Araujo, D.S.D. 2005. Formações vegetais da Restinga da Marambaia, Rio de Janeiro. Pp. 67-120. In: L.F.T. Menezes; A.L.Peixoto \& D.S.D. Araujo. História Natural da Marambaia. Seropédica, EDUR.

Moraes, R.M., Delitti, W.B.C. \& Struffaldi-de Vuono, Y. 1999. Litterfall and litter nutrient content in two Brazilian Tropical Forests. Revista Brasileira de Botânica 22:9-16.

Moreno, M.R.; Nascimento, M.T. \& Kurtz, B.C. 2003. Estrutura e composição florística do estrato arbóreo em duas zonas altitudinais na mata atlântica de encosta da região do Imbé, RJ. Acta Botanica Brasílica 17(3): 371-386.

Mueller-Dombois, D. \& Ellemberg, H. 1974. Aims and Methods of Vegetation Ecology. New York, John Wiley \& Sons.

Nascimento, M.T. \& Lima, H.C. 2008. Floristic and structural relationships of a tabuleiro forest in northeastern Rio de Janeiro, Brazil. Pp 395-416. In: Thomas, W.W. (ed.). The Atlantic coastal forest of northeastern Brazil. New York, New York Botanical Garden Press.

Oliveira Filho, A.T., Curi, N., Vilela, E.A. \& Carvalho, D.A. 2001. Variation in tree community composition and structure with changes in soil properties within a fragment of semideciduous forest in south-eastern Brazil. Edinburgh Journal of Botany 58: 139-158

Oliveira-Filho, A.T. \& Ratter, J.A. 2000. Padrões florísticos das matas ciliares da região do cerrado e a evolução das paisagens do Brasil central durante o Quaternário tardio. Pp. 73-89. In: Rodrigues, R.R. \& Leitão-Filho, H.F. (eds). Matas ciliares: Conservação e recuperação. São Paulo, Universidade de São Paulo.

Pagano, S.N. \& Durigan, G. 2000. Aspectos da ciclagem de nutrientes em matas ciliares do oeste do estado de São Paulo, Brasil. Pp. 109123. In: Rodrigues, R.R.\& Leitão-Filho, H.F. (eds.). Matas ciliares: Conservação e recuperação. São Paulo, Universidade de São Paulo.

Pereira, O.J. \& Araujo, D.S.D. 2000. Análise florística das restingas dos estados do Espírito Santo e Rio de Janeiro. Pp. 25-63. In: Esteves, F.A. \& Lacerda, L.D. (eds.). Ecologia de restingas e lagoas costeiras. Macaé, NUPEM/UFRJ.

Pereira, O.J. \& Gomes, J.M.L. 1994. Levantamento florístico das comunidades vegetais de restinga no município de Conceição da 
Barra, ES. Pp. 67-78. In: Anais do III Simpósio sobre Ecossistemas da Costa Brasileira. Serra Negra, 1993. São Paulo, ACIESP. v. 3.

Pereira, O.J. 1990. Caracterização fitofisionomica da restinga de Setiba, Guarapari, E.S. Pp. 207-219 In: Anais do II Simpósio de ecossistemas da costa sul e sudeste brasileira: estrutura, função e manejo. Águas de Lindóia, 1990. São Paulo, ACIESP. v.3.

Pereira, O.J.; Borgo, J.H.; Rodrigues, I.D. \& Assis, A.M. 2000. Composição florística de uma floresta de restinga no município da Serra-ES. Pp. 74-83. In: Anais do V Simpósio de Ecossistemas Brasileiros: Conservação. Vitória, 2000. São Paulo, ACIESP. v.3.

Ponnamperuma, F.N. 1984. Effects of flooding on soils. Pp. 10-46. In: Kozlowski, T.T. (ed.). Flooding and plant growth. London, Academic Press.

Rodrigues, R.R. \& Shepherd, G.J. 2000. Fatores condicionantes da vegetação ciliar. Pp.101-108. In: Rodrigues, R.R. \& Leitão-Filho, H.F. (eds.). Matas ciliares: Conservação e recuperação. São Paulo, Universidade de São Paulo.

Roncarati, H. \& Menezes, L.F.T. 2005. Marambaia, Rio de Janeiro: Origem e evolução. Pp. 15-38. In: Menezes, L.F.T. Peixoto, A.L. \& Araujo, D.S.D. História Natural da Marambaia. Seropédica, EDUR.

Sá, C.F.C. \& Araujo, D.S.D. 2009. Estrutura e florística de uma floresta de restinga em Ipitangas, Saquarema, Rio de Janeiro, Brasil. Rodriguesia 60 (1):147-170.

Scarano, F. R. 1998. A comparison of dispersal, germination and establishment of woody plants subjected to distinct flooding regimes in Brazilian flood-prone forest and estuarine vegetation. Oecologia Brasiliensis 4: 177-194.

Scarano, F. R. 2000. Marginal plants: Functional ecology at the Atlantic forest periphery. Pp. 176-182. In: Cavalcanti, T.B. \& Walter, B.W. (orgs.). Tópicos atuais em Botânica: Palestras convidadas do $51^{0}$ Congresso Nacional de Botânica. Brasília, Embrapa.

Scarano, F. R. 2002. Structure, function and floristic relationships of plant communities in stressful habitats marginal to the brazilian atlantic rainforest. Annals of Botany 90:517-524.

Scarano, F. R.; Rios, R. I. \& Esteves, F. A. 1998. Tree species richness, diversity and flooding regime: case studies of recuperation after anthropic impact in brazilian flood-prone forests. International Journal of Ecology and Environmental Sciences 24:223-235.

Scarano, F.R; Duarte, H.M; Ribeiro, K.T.; Rodrigues, P.J.F.P.; Barcellos, E.M.B.; Franco, A.C.; Brulfert, J.; Deléens, E \& Lüttge, U. 2001. Four sites with contrasting environmental stress in southeastern Brazil: relations of species, life form diversity, and geographical distribution to ecophysiological parameters. Botanical Journal of the Linnean Society 136: 345-364

Scherer, A.; Maraschin-Silva, F. \& Baptista, L.R.M. 2005. Floristica e estrutura do componente arbóreo de matas de restinga arenosa no Parque
Estadual de Itapuã, RS, Brasil. Acta Botânica Brasilica 19(4): 717-726.

Schöngart, J.; Piedade, M.T.F.; Ludwigshausen, S.; Hornas, V. \& Worbes, M. 2002. Phenology and stem-growth periodicity of tree species in Amazonian floodplain forests. Journal of Tropical Ecology 18(1): 581-597.

Shepherd, G. J. 1996. FITOPAC 1: Manual do usuário. Campinas, Unicamp.

Silva, A.C.; Berg, E.V.D.; Higuchi, P. \& Oliveira-Filho, A.T. 2007. Composição florística de florestas inundáveis das regiões sudeste e sul do Brasil. Revista brasileira de Botânica 30(2): 257-269.

Silva, S.M. \& Britez, R.M. 2005. A vegetação da planície costeira. Pp. 4984. In: Marques, M.C.M. \& Britez, R.M. (orgs.) História natural e conservação da Ilha do Mel. Curitiba, Ed. UFPR.

Silva, S.M.; Britez, R.M.; Souza, W.S. \& Joly, C.A. 1994. Fitossociologia do componente arbóreo da floresta de restinga da Ilha do Mel, Paranaguá, PR. Pp. 33-46. In: Anais do III Simpósio sobre Ecossistemas da Costa Brasileira. Serra Negra, 1993. São Paulo, ACIESP.v. 3.

Spiegal, M.R. 1977. Estatística. McGraw-Hill do Brasil, São Paulo.

Sugiyama, M. 1998. Estudo de florestas da restinga da Ilha do Cardoso, Cananéia, São Paulo, Brasil. Boletim do Instituto de Botânica 11: 119-159.

Sztutman, M. \& Rodrigues, R.R. 2002. O mosaico vegetacional numa área de floresta contínua da planície litorânea, Parque Estadual da Campina do Encantado, Pariquera-Açu, SP. Revista Brasileira de Botânica 25(2): 161-176.

Toniato, M.T.Z.; Leitão-Filho, H.F. \& Rodrigues, R.R. 1998. Fitossociologia de um remanescente de floresta higrófila (mata de brejo) em Campinas, SP. Revista Brasileira de Botânica 21(2): 197-210.

Valentin, J.L. 2000. Ecologia numérica. Rio de Janeiro, Ed. Interciência.

Van Raij, B. 1969. A capacidade de troca de cátions das frações orgânicas e minerais em solos. Bragantia 28(8): 85-112.

Waechter, J.L \& Jarenkow, J.A. 1998. Composição e estrutura do componente arbóreo nas matas turfosas do Taim, Rio Grande do Sul. Biotemas 11(1): 45-69.

Waechter, J.L. 1990. Comunidades vegetais de restingas do Rio Grande do Sul. Pp. 228-248. In: Anais do II Simpósio de Ecossistemas da Costa Sul e Sudeste Brasileira: estrutura, função e manejo. Águas de Lindóia, 1990. São Paulo, ACIESP. v. 3.

Waechter, J.L.; Muller, S.C.; Breier, T.B \& Venturi, S. 2000. Estrutura do componente arbóreo em uma floresta subtropical de planície costeira interna. Pp. 92- 112. In. Anais do V Simpósio de Ecossistemas Brasileiros: Conservação. Vitória, 2000. São Paulo, ACIESP. v.3.

Whitmore, T.C. 1982. On pattern and process in forests. Pp. 45-59. In: Newman, E.I. (ed.). The plant community as a working mechanism. Oxford, Blackwell Scientific Publications. 